\title{
Teoría y práctica en la historia de las ideas. Implicaciones para la antropología aplicada
}

Theory and practice in the history of ideas. Implications for Applied Anthropology

\author{
Carlos Giménez Romero \\ Catedrático de Antropología Social. Universidad Autónoma de Madrid (España) \\ carlos.gimenez@uam.es
}

\author{
30 ANIVERSARIO DE LA GAZETA DE ANTROPOLOGÍA \\ NÚMERO COORDINADO POR FRANCISCO CHECA OLMOS Y CELESTE JIMÉNEZ DE MADARIAGA
}

\begin{abstract}
RESUMEN
Este texto es el primero de una serie de trabajos del autor orientados a la fundamentación de la antropología práctica. Se parte de que la fundamentación conceptual de la ciencia social aplicada en general y, en particular, de la antropología aplicada, implicada y con orientación pública, requiere de una posición razonada con respecto a la relación entre teoría y práctica. En el texto se revisan las aportaciones de Aristóteles, Vico, Kant y Marx a partir de cuatro obras claves, toda ellas auténticos hitos en lo que se refiere a los nexos entre pensamiento y acción. En el ensayo se argumenta que es preciso superar la concepción hegemónica de relación unidireccional -de la teoría a la práctica- que reduce dicha conexión relación a la mera cuestión de la aplicación. A partir de los autores mencionados, y como hilos conductores de sucesivos ensayos sobre otros autores y obras claves, se plantea la triple necesidad de: a) reconocer la pluralidad de saberes, b) precisar la noción de teoría y práctica, c) otorgar primeridad a la práctica y d) considerar el conjunto de vínculos existentes entre pensamiento y acción. Las conexiones entre práctica y teoría se sistematizan en cuatro procesos y momentos: (I) la generación de toda teoría en contextos prácticos, (II) el uso y aplicación de los conocimientos, (III) la validación o verificación de las teoría (también) mediante la praxis, y (IV) la teorización (también) desde la práctica. El ensayo culmina con una propuesta de articulación de teoría y práctica acorde con el acervo extraído y con las siguientes características: hacia una articulación científicamente fundamentada, de carácter dialéctico, éticamente implicada, con orientación pública y técnicamente operativa.
\end{abstract}

\begin{abstract}
This text is the first in a series of works of the author focused on the foundation of practical anthropology. It assumes that the conceptual basis of applied social science in general and, in particular, applied anthropology, and public guidance involved, requires a reasoned position regarding the relationship between theory and practice. The text reviews the contributions of Aristotle, Vico, Kant, and Marx from four key works, all these milestones with regard to the links between thought and action. The essay argues that we must overcome the hegemonic conception of the one-way relationship -from theory to practicewhich reduces the connection related to the mere matter of the application. From the abovementioned authors, and as threads of successive trials on other key authors and works, there is the dire need to: a) recognize the plurality of knowledge, b) define the concept of theory and practice, c) grant firstness to practice d) consider the set of links between thought and action. The connections between practice and theory are systematized into four processes and times: (I) the generation of every theory in practical contexts, (II) the use and application of knowledge, (III) the validation or verification of the theory (also) through praxis, and (IV) theorizing (also) from the practice. The essay ends with a joint proposal of theory and practice in line with the acquis and drawn from the following features: towards a joint science-based, dialectical nature of ethically concerned, public-oriented and technically operational.
\end{abstract}

thought and action | knowledge and transformation | praxis | practical anthropology | knowledge dialogue

\section{Introducción (1)}

Este texto es el primero de una serie de trabajos orientados a la fundamentación teórica de la antropología aplicada. Desde el principio hemos de aclarar dos cosas. Por un lado, que el interés por 
identificar y sistematizar las bases conceptuales de la antropología aplicada se ubica en una motivación más amplia hacia el conocimiento científico aplicado en general y, más en particular, hacia el aprovechamiento práctico y ético de las ciencias sociales. También deseo aclarar que, aunque las reflexiones que siguen están centradas en la antropología aplicada, las temáticas que se abordan y las aportaciones de los autores son de claro interés para un campo más amplio y plural, esto es, para la antropología implicada o comprometida, la antropología de orientación pública y la antropología profesional más allá de la academia.

Esto es, aunque nuestra revisión y propuesta está focalizada en la antropología aplicada, la reflexión sobre teoría y práctica es necesaria y relevante en un contexto mucho más amplio de líneas y énfasis que quizás podrían englobarse bajo el rótulo de antropología practica o de praxis antropológica (para la distinción e interrelación entre esas modalidades del hacer antropológico puede verse Giménez 2012).

El punto de partida de la reflexión que sigue es el convencimiento de que la fundamentación conceptual de la ciencia social aplicada en general, y en particular de la antropología aplicada, implicada y con orientación pública, ha de venir -al menos en mi consideración- de una posición rigurosa y ampliamente razonada y argumentada con respecto a la relación y articulación entre teoría y práctica. He ahí el nudo gordiano de ese posible basamento del trabajo aplicado en el rigor teórico.

También en este asunto es conveniente una precisión previa. He de enfatizar desde el principio la diferencia que en este ensayo, y los que le seguirán, se establece entre "relación" y "articulación". Un cosa es la relación que de hecho existe en la sociedad entre las elaboraciones teóricas de las ciencias y el conjunto de las prácticas, esto es, la relación intelectual, sociopolítica o simbólica entre teoría y práctica; y otra cosa la articulación que el sujeto cognoscente e investigador, el activista o practitioner quiere o desea establecer entre ambas. La "relación" lo es de facto: es lo que ha habido o hay de hecho entre lo que denominaré el mundo de la práctica y el mundo de la teoría; en esa dimensión del problema es preciso analizar dicha relación de facto como un objeto de estudio más dentro del campo de la historia de las ideas, de la ciencia o del conocimiento. La "articulación", sin embargo, es una categoría normativa, se sitúa en el ámbito del deber ser, y depende no sólo de la reflexión sino sobre todo de la voluntad del sujeto.

Este ensayo aborda, en la perspectiva de la historia de las ideas, los planteamientos sobre teoría y práctica en una serie reducida de autores y obras claves, todos ellos considerados especialmente influyentes en la historia del pensamiento (especialmente en filosofía, humanidades y pensamiento social) y decisivos en la materia que nos ocupa. No se trata de un análisis mínimamente exhaustivo sino de una selección intencionada y una secuencia de momentos claves en la reflexión sobre pensamiento y acción. Los hitos claves de esa secuencia que aquí se aborda son los siguientes:

- La concepción de Aristóteles sobre diferentes modalidades de los saberes, sobre todo lo relativo a theoría, techné y phronesis, y especialmente lo formulado por el estagirita en su Ética a Nicómaco (siglo IV a.d.C).

- Los planteamientos del verum factum de Giambattista Vico expuestos en su Scienza Nuova (1754) y parte esencial de su propuesta epistemológica y metodológica para una renovación e impulso de las ciencias.

- La reflexión de Immanuel Kant sobre teoría y práctica, sobre todo lo expuesto en su disertación de 1793 titulada En torno al tópico: "tal vez eso sea correcto en teoría pero no sirve para la práctica".

- Las propuestas respecto a teoría, práctica y praxis por parte de Carlos Marx, especialmente en sus Tesis sobre Feuerbach (1845).

A partir de la revisión de las aportaciones de estos autores claves, y de los que serán considerados en los próximos trabajos (2), tenemos previsto abordar las principales implicaciones de todo ello para las ciencias sociales aplicadas en general y, más concretamente, para la antropología aplicada e implicada, la antropología profesional más allá de la academia y la antropología de orientación pública (3). Quisiera 
adelantar aquí tres de esas implicaciones, puesto que ello servirá para ubicar los énfasis (en cursiva) que iremos haciendo en la lectura de los autores clave.

Por un lado, el estudio de los debates sobre teoría y práctica -y sobre todo la fundamentación de una praxis antropológica- obliga a abordar la definición de los términos de la relación/articulación -esto es, qué entender por teoría y por práctica- puesto que, tal y como hemos veremos, según se entienda cada uno de ellos, así se establecerá la relación y/o articulación. Es más, es preciso aclarar incluso cómo se entiende la propia relación o, en su caso, la propuesta de articulación.

Por otro lado, y ésta es la segunda implicación de la revisión realizada de autores y posiciones, es preciso hacer una lectura de la cuestión de la relación/articulación de práctica y teoría no ya desde la historia de las ideas sino desde una perspectiva sincrónica o estructural, esto es, desde el ángulo de cuáles son los asuntos, dimensiones o momentos centrales en la relación entre teoría y práctica. Como se verá en las páginas que siguen hemos ideo identificando cuatro de esos temas o momentos primordiales: (I) el contexto práctico de la misma generación del conocimiento, (II) el proceso propiamente dicho de aplicación de la teoría, (III) todo lo relativo a la validación del conocimiento en la práctica, y (IV) la cuestión del proceso y posibilidades de teorización desde la práctica.

El hilo conductor mediante el que nos guiamos en esa reflexión sobre la pluralidad de conexiones entre teoría y práctica es la necesidad de superar la concepción mayoritaria, y dominante, de unilateralidad y simplicidad del planteamiento sobre las relaciones entre teorías y prácticas. Esa concepción, habitual y hegemónica, se expresa sobre todo en dos aspectos: primero, reducir la relación a solo un asunto (el proceso unidireccional de la aplicación de la teoría a la práctica) y, segundo, otorgar siempre -salvo las excepciones que veremos- la primeridad a la teoría. Esa concepción hegemónica de reduccionismo y unidireccionalidad forma parte de las relaciones generales de dominación política, social e ideológica, y de las relaciones particulares de poder en el mundo de la gestión política y pública de los conocimientos y de las corporaciones profesionales y académicas.

Para superar, desde un esfuerzo contrahegemónico y hacia nuevos consensos emancipadores, esa concepción predominante, reductiva y unidireccional, la propuesta que se hace en éste y sucesivos trabajos es la de considerar y explicitar, en las relación/articulación entre teoría y práctica, no sólo la instancia habitual (aplicación de la teoría) en la que la primeridad de la teoría es clara, sino las otras tres recién mencionadas: la generación del conocimiento, su validación y la teorización desde la práctica, las cuales permiten: a) otorgar la primeridad a la práctica, y b) establecer una bi o multi direccionalidad dialéctica entre práctica y teoría.

Finalmente, una tercera implicación y tarea necesaria a partir de la revisión realizada es hacer una síntesis con aquellos elementos ya expuestos que se consideren más adecuados, rigurosos, sólidos y operativos, formulando una propuesta de articulación de teoría y práctica (no sólo de relación de hecho) que esté acorde con el acervo extraído y configurado a partir de la historia de las ideas. En ese sentido, la propuesta que se hace es la de configurar en los trabajos de la antropología práctica una articulación de práctica y teoría con cinco atributos o características: una articulación científicamente fundamentada, de carácter dialéctico, éticamente implicada, con orientación pública y técnicamente operativa.

\section{Aristóteles y su Ética a Nicómaco: theoría, phrónesis y techné}

Ha habido diversas concepciones en la historia del pensamiento acerca de la relación general entre pensamiento y acción, así como entre teoría y práctica. Desde nuestra perspectiva contemporánea y desde el interés por fundamentar la praxis antropológica, parecen cruciales como hilos conductores dos líneas de pensamiento complementarias que, en ocasiones, se entrecruzan y solapan: a) la que afirma la existencia de diversas formas de conocimiento y saber, que arranca en Aristóteles y su concepción de theoría, phrónesis y techné, y desde la que puede ubicarse la relación entre teoría y práctica en el ámbito del diálogo y colaboración de saberes y conocimientos; y b) la que considera la práctica como instancia de conocimiento e incluso como instancia verificadora de las teorías, una línea que va de Giambattista 
Vico y su verum factum a Carlos Marx y la praxis revolucionaria, y en la que puede establecerse una relación dialéctica entre ambas.

\subsection{La no separación entre pensamiento y acción}

En los pensadores de la Grecia clásica la filosofía y ciencia, por un lado, y la ética y virtud por otro, no estaban tan diferenciadas como lo han estado posteriormente. Hoy día cuando hacemos ciencia o teoría las diferenciamos radicalmente del mundo de los valores. Concebimos que las actividades principales del pensamiento científico consisten en describir, medir, analizar e interpretar, pero no incluimos entre ellas las de valorar, sugerir o actuar con inteligencia o virtud. Afirmamos que el científico debe controlar su subjetividad y hacemos coincidir ésta con sus valores. No era así entre los pensadores griegos.

Entre nosotros, el sabio, filósofo o científico, es concebido predominantemente como alguien que piensa de forma lógica y rigurosa, tratando de controlar su subjetividad, alguien que, en cualquier caso, no conecta su actividad de pensamiento con el ejercicio general de la virtud, o de tal o cual virtud. La "persona investigadora" y la "persona virtuosa" están hace tiempo disociadas. Pero no era así en los pensadores de la Grecia clásica.

Así, por ejemplo, para Sócrates -si seguimos lo que Platón nos dice sobre el pensamiento socrático en su Protágoras- saber y virtud se identifican; la búsqueda de sí mismo es simultáneamente la búsqueda de lo verdadero y de la mejor manera de vivir; la investigación del saber y de la virtud van juntas. Para Sócrates, una ciencia que no sea capaz de dirigir a la persona humana hacia la virtud, o que la pueda dejar a merced de los instintos o impulsos sensibles, no es tal ciencia. Para el maestro Sócrates, en la ignorancia es donde está la base o causa de toda culpa y vicio; el cálculo equivocado de quien obra mal es debido a su ignorancia o, dicho de otra manera, quien verdaderamente sabe, calcula bien y opta por aquellos placeres y satisfacciones que hacen daño y que no le dañan.

Ahora bien, algo sobresaliente en Aristóteles es que si ciencia y virtud aparecen relacionados (como en Sócrates, Platón y otros filósofos de la Grecia clásica) esta conexión no es dicotómica -entre saber teórico y saber práctico- sino que en el dominio de la práctica va a diferenciar dos saberes: la phrónesis y la techné, con lo cual la relación entre teoría y práctica se presenta de una forma novedosa respecto a los antecedentes y desde luego bastante más compleja que los binomios posteriores teoría/práctica. Phrónesis ha sido traducida como sabiduría moral o como prudencia. Techné ha sido traducido como saber técnico o como arte.

\subsection{Reevaluación contemporánea de la concepción aristotélica de la pluralidad de saberes}

Este notable aspecto del pensamiento aristotélico -la que versa sobre sabiduría y virtud- ha sido reevaluada desde la década de los noventa del siglo XX por varios pensadores y desde distintos ámbitos del pensamiento. Nos interesa particularmente la inspiración que en esa línea del pensamiento de Aristóteles han encontrado, por una parte, filósofos de la hermenéutica como Hans-Georg Gadamer en su Verdad y Método (para fundamentar su filosofía de la práctica) (4), en especialistas en Aristóteles como Pierre Aubenque o del filósofo e historiador de la ciencia Stephen Toulmin, especialmente lo expuesto en Beyond Theory (texto colectivo coordinado junto a Bjorn Gustavsen, sociólogo noruego y especialista en investigación-acción). En sociología y antropología destacaríamos además, en esta revalorización de la concepción plural de Aristóteles, primero, las aportaciones del sociólogo y planificador danés Bent Flybjerg, autor de Making Social Science Matter. Why Social Inquiry fails and how it can succeed again ,en la que, asumiendo los fallos de la investigación social en su contribución pública, postula la alternativa de una ciencia social phronética (phronetic social science), esto es, una ciencia social que incorpora la sabiduría práctica y la acción éticamente correcta.

Finalmente, y de especial interés para los antropólogos, destacan las propuestas de David Greenwood (2002), especialista en investigación acción participativa (IAP) y quien, tratando de superar diferentes binomios simplificadores en la historia de la antropología -como teórico/aplicado, ciencia pura/ciencia comprometida, observador/involucrado, antropólogo real/antropólogo nativo; informante/co-sujeto- y haciéndose eco de los trabajos de Toulmin, Gustavsen y Flybjerg, muestra el valor actual y la utilidad de 


\subsection{Theoría, phrónesis y techné en la Ética a Nicómaco}

La obra principal donde aparece la concepción aristotélica de las diferentes formas de conocimiento, o más exactamente de actividad o disposición donde se utiliza la razón y se expresa la verdad, es la Ética a Nicómaco, así titulada por el nombre de la persona a quien iba dedicada, y que constituye una de las tres obras claves sobre ética en el gran pensador. Tomemos nota de ello, insistiendo en lo que decíamos anteriormente sobre que no siempre hubo la actual disociación radical y hegemónica entre pensamiento y virtud: es como si hoy día, las teorías de un/a autor/a sobre conocimiento, razón o verdad estuviera ubicada en su manual de ética.

Sinteticemos lo que plantea al respecto Aristóteles en la Ética a Nicómaco. El capítulo 3 del Libro VI se abre con esta afirmación: "Admitamos que existen cinco formas de actividad, por medio de las cuales el alma expresa la verdad. Éstas son: el arte, la ciencia, la prudencia, la discreción o sabiduría, la inteligencia" (Aristóteles 2010: 211) (5). Respecto a la ciencia, Aristóteles indica, ya en ese mismo capítulo, que su naturaleza "se nos manifiesta claramente si queremos expresarnos con precisión y no fiarnos de vagas semejanzas" (ídem). Junto a ese atributo de claridad y precisión, añade como característica de la ciencia su carácter necesario, no plural ni opinático: "Todos nosotros, sin excepción, creemos que lo que nosotros sabemos no admite ser de otra manera. En cuanto a las cosas que admiten cambios, desde el momento que escapan a las miradas del espíritu, nosotros no podemos pronunciarnos sobre ellas, sobre su existencia o no existencia" (Aristóteles 2010). Es más: "lo que es el objeto de la ciencia existe de toda necesidad y tiene, por consiguiente, un carácter eterno" (Aristóteles 2010; cursivas mías, de Carlos Giménez).

El capítulo 4 de ese mismo Libro VI lo dedica al arte. Previo a su definición, Aristóteles distingue entre creación y acción, remitiéndose sobre esto a sus tratados exotéricos. Catalá y Lorente (2010), en su edición de la Ética Nicomaquea, incluyen una nota en la que explican así esta diferencia: la creación es la "acción operativa en cuanto tiene un resultado exterior", mientras que la acción es la "acción propiamente tal, considerada sobre todo en su aspecto subjetivo". Es la creación la que se refiere al arte o techné: "Supuesto que la arquitectura es un arte, que este arte se define por una disposición, acompañada de razón, dirigida a la creación; puesto que todo arte es una disposición acompañada de razón y dirigida a la creación, y puesto que toda disposición de esta clase es un arte, el arte y la disposición acompañada de razón conforme a la verdad se confunden" (Aristóteles 2010: 213; cursivas mías). A pesar de cierta dificultad con respecto a la claridad del texto, resaltemos aquí que el arte o techné van acompañados de razón y que operan conforme a la verdad. Dicho de otra manera, la razón y la verdad no son patrimonio exclusivo de la ciencia (theoría) que Aristóteles define en el capítulo 3.

¿Y qué más afirma Aristóteles del arte o techné? Pues lo siguiente: "Por otra parte, todo arte genera una obra y busca los medios técnicos y teóricos de crear una cosa que pertenece a la categoría de los posibles y cuyo principio reside en la persona que lo ejecuta y no en la obra realizada" (Aristóteles 2010: 213; cursivas mías). Así pues, en esta segunda "forma de actividad" también hay teoría, no sólo técnica, aunque solo sea teoría como medio, como medio para producir la obra. Por otra parte, hay una contraposición entre la categoría de necesario, propio de la ciencia, y la categoría de lo posible donde se encuentra la creación, el arte, la techné. En efecto, Aristóteles lo explicita: "Pues el arte no hace referencia a lo que existe o se produce de manera necesaria, no más que a lo que existe por efecto de la sola naturaleza, ya que todas las cosas de este tipo tienen en sí mismas su principio" (Aristóteles 2010). Finalmente, el principio de esa actividad no lo vamos a encontrar en la obra realizada sino en la persona, en su creatividad.

Concluye el capítulo 4 con la siguiente síntesis definidora: "el arte es una disposición capaz de creación, acompañada de razón verdadera; por el contrario, defecto o falta de arte es esta misma disposición servida por un razonamiento erróneo en el campo de los posibles" (Aristóteles 2010; cursivas mías).

El capítulo 5 lo dedica el estagirita a la prudencia o phrónesis, la tercera forma de "actividad, por medio 
de las cuales el alma expresa la verdad", si recordamos su planteamiento en el capítulo 3. ¿Cuál es el punto de partida para caracterizar esta otra actividad dotada de verdad? Aristóteles recurre ni más ni menos que a la concepción de la gente: "Estaremos en disposición de discernir lo que es la prudencia estudiando desde el comienzo a quiénes llama la gente prudentes" (Aristóteles 2010: 214). Es interesante esa vía de reflexión tan propia de la etnografía y la antropología, y que conecta con las reflexiones de Vico, Dewey, Gramsci y otros sobre la conciencia de las cosas, la experiencia o el sentido común (si bien estas categorías no se equiparan, como iremos viendo).

¿Y qué es lo que encuentra Aristóteles observando y estudiando la concepción popular en ese punto?

"Parece con razón que lo que los caracteriza (a las personas dotadas de prudencia) es la capacidad de decidir de la manera más conveniente lo que es útil y bueno para ellos mismos, y no de modo parcial, como en el caso de lo que se refiere a la salud o al vigor físico, sino, en general, en lo que concierne a la felicidad. Prueba de ello es que llamamos prudentes en algún orden de cosas a aquellos que, por sus cálculos exactos, alcanzan un fin honroso en cuestiones en que no interviene el arte, de tal manera que el hombre bien dotado del poder de reflexionar sería la misma prudencia" (Aristóteles 2010: 214; cursivas mías).

Aquí ya no estamos en el reino de lo necesario, de las verdades inmutables, de los silogismos y las demostraciones (theoría) sino que estamos, como ocurre con el arte o techné, en el campo de lo posible. Ahora bien, mientras el arte o techné producen algo y la habilidad del sujeto que la posee consiste precisamente en eso -y para ello se dotan de "razón verdadera"- la prudencia se caracteriza por la capacidad de decisión, de juicio acertado o ponderado, acerca de lo útil y bueno, acerca de aquello que conduce al máximo fin o bien supremo (la felicidad) y para ello se requiere de "cálculos exactos", con lo que está presente, de nuevo, la racionalidad y la expresión de la verdad.

Verdaderamente interesante y sugerente estas apuestas de Aristóteles, concediendo valor, y valor de razón y de verdad, a la capacidad de estimar, valorar, decidir, produciendo lo útil o práctico, lo bueno dador de felicidad. Si la ciencia o theoría aspira al descubrimiento de la verdad necesaria, abstracta, eterna, válida aquí y allá, y si el arte o techné persigue creativamente la obra realizada requiriendo para ello de "razón verdadera" y no de "razonamiento erróneo", la prudencia o phrónesis nos acerca ni más ni menos que a la felicidad, al mundo mejor, mediante la capacidad de decisión y el juicio ecuánime y ponderado.

Aristóteles nos muestra la esencia deliberativa de la phrónesis y cómo ello la diferencia de la ciencia, y al tiempo, nos indica su especificidad:

"nadie delibera sobre aquello que tiene un carácter de necesidad y que se halla fuera de su alcance. Por eso, puesto que la ciencia va acompañada de demostración de aquello cuyos principios no son necesarios -ya que ahí todo es susceptible de cambio- , y puesto que, en fin, no es posible deliberar sobre lo que posee un carácter de necesidad, resulta de ello que la prudencia no podría implicar ni la ciencia ni el arte. No podrá ser una ciencia, porque lo que es del orden de la acción es susceptible de cambio, como tampoco podrá ser un arte, porque acción y creación son de muy distinta naturaleza. Resta, pues, que la prudencia sea una disposición, acompañada de razón justa, dirigida hacia la acción y con referencia a lo que es bueno o malo para el hombre" (Aristóteles 2010: 214; cursivas mías).

En esta última frase encontramos quintaesenciados tres rasgos claves de la phrónesis o prudencia: a) va acompañada de "razón justa", b) va dirigida a la acción, y c) se refiere a lo bueno y lo malo.

Si salimos un momento del razonamiento y las palabras del gran filósofo y pensamos desde las ciencias sociales implicadas y aplicadas, observamos la riqueza que estos planteamientos ofrecen, y se comprende los motivos del proceso de reevaluación en los últimos quince años de este aspecto del pensamiento aristotélico por diversos filósofos y científicos sociales. En efecto, la ciencia y la teoría pueden verse enriquecidas por la actividad de sujetos -que puede ser el propio científico o, más frecuentemente, otros sujetos- que disponen bien de techné (con capacidad de crear un producto) bien 
Con esto último aparece la reflexión y razonabilidad (6) -"razón verdadera", "razón justa" en los términos de Aristóteles- junto a las categorías de valor (y ya no solo con relación a las categorías descriptivas y analíticas) y, por otro lado, no solo con relación a los teóricos y las personas de ciencia sino abriéndose al conjunto de los actores que tengan esas capacidades. Desde nuestra consideración, ambas cosas son claves de cara a la fundamentación de las ciencias aplicadas en general y, en particular, de las ciencias sociales aplicadas, y de cara a la estructuración del trabajo aplicado o práctico del científico social.

Lo primero -esto es, que la razón esté presente en la ciencia, el arte y la prudencia, y que ésta última se refiera a la felicidad, a lo deseable o mejor- permite no separar drástica o artificialmente teoría y práctica, ciencia y aplicación, por cuanto el/la investigador/a, además de describir, analizar e interpretar, puede ir más allá, internándose en el campo de lo valorativo, poniendo su conocimiento y saber a disposición de la transformación y mejoramiento de la realidad. Sin duda, esta implicación social y ética del científico conlleva cuestiones de considerable complejidad que no podemos discutir aquí; lo que queremos mostrar ahora es que la concepción de Aristóteles abre una vía para fundamentarlo.

Lo segundo -esto es, que si partimos de teoría, techné y phrónesis los actores de la reflexión ya no son sólo los científicos- permite a su vez por un lado buscar que los investigadores- o al menos parte de ellos- tengan también capacidades de techné y phrónesis y, sobre todo, permite fundamentar formas de investigación participativa y de colaboración a la hora de realizar los estudios y las etnografías, lo que en otro lugar he planteado como diálogo de saberes a la hora de hacer antropología práctica, implicada, aplicada o de orientación pública (Giménez 2012).

Tras poner como ejemplo a imitar la prudencia de Pericles y personas de esa clase, afirma: "Estimamos que con estas cualidades son verdaderamente capaces de dirigir una familia o una ciudad. De aquí la palabra sofrosine (buen sentido), que empleamos para significar que esta cualidad salvaguarda la mente o el recto sentido" (Aristóteles 2010: 215; cursivas mías). Así pues, la prudencia requiere saber salvaguardar los principios, ideas y conceptos de las presiones de la vida cotidiana. Encuentro esta idea de gran interés tanto para el investigador/antropólogo a la hora del trabajo aplicado e implicado (saber mantener la ponderación y ecuanimidad en y durante la experiencia práctica) como a la hora del diálogo de saberes, sabiendo identificar, valorar y aprender de los actores con la disposición de phrónesis.

Sobre este punto, el razonamiento de Aristóteles continúa así: "En efecto, (la prudencia) es la guardiana de las ideas de esta clase; no todos los conceptos, en efecto, son alterados o tergiversados por las impresiones de placer o de dolor: testigo de ello lo es el que afirma o niega que el triángulo tienes sus ángulos iguales a dos rectos. Solamente se ven alterados los conceptos que dicen referencia a la acción moral, porque los principios, en lo que concierne a la acción moral, son el fin en vista del cual se realiza la acción" (Aristóteles 2010: 215; cursivas mías). También esta línea de razonamiento me parece de gran valor heurístico y práctico puesto que, traducido a la cuestión que he planteado en otros escritos, diferencia -desde mi lectura- entre conceptos analíticos (que no son "alterados o tergiversados por las impresiones de placer o de dolor") y conceptos axiológicos (que se ven alterados porque "dicen referencia a la acción moral"). En los proyectos o experiencias de antropología aplicada es absolutamente imprescindible explicitar todo lo relativo a los valores (de los sujetos participantes y del equipo científico social), así como definir con nitidez cómo se emplean y manejan conceptos cargados de valor y dimensión ética como, por ejemplo, desarrollo, integración, ciudadanía, interculturalidad, convivencia o justicia.

Concluyendo los razonamientos del capítulo $\mathrm{V}$ del Libro Sexto de la Ética Nicomaquea, Aristóteles vuelve a definir así la phrónesis: "Por eso se ve uno obligado a concluir que la prudencia es una disposición, acompañada de razón y verdad, dirigida a la acción y con referencia a los bienes humanos" (Aristóteles 2010: 215; cursivas mías). De nuevo los tres rasgos nucleares que vimos antes.

\subsection{Una lectura contemporánea de Theoría, Techné y Phrónesis}

Para concluir este primer apartado dedicado a Aristóteles y su Ética a Nicómaco expongo a continuación 
una síntesis de la lectura contemporánea a la que me refería al principio. La siguiente tabla, basada en la síntesis realizada por David Greenwood (2002) a partir de las obras citadas: Toulmin y Gustavsen (1996) y Flyvberg (2001); compara esas tres modalidades de saber en un conjunto variado de aspectos. en próximo ensayo analizaremos detenidamente la obra de estos autores y sus propuestas para la ciencia social implicada.

\section{Tabla 1}

Una lectura contemporánea de la distinción de Aristóteles sobre Theoría, Techné y Phrónesis

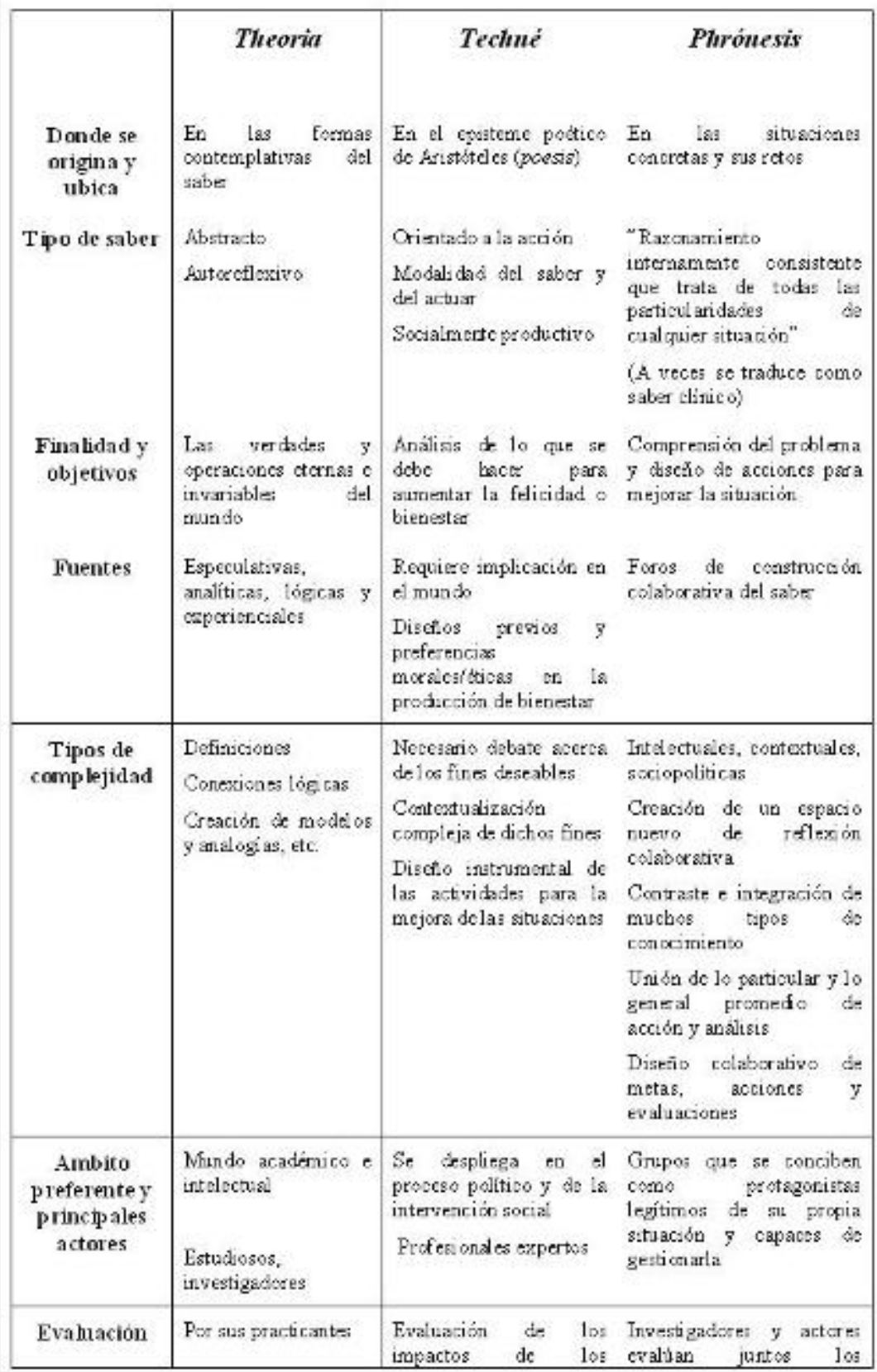

Fuente: elaboración e interpretación propia a partir de Greenwood (2002: 13-15), quien a su vez sintetiza las aportaciones de Toulmin y Gustavsen (1996) y de Flyvberg (2001)

\subsection{Aprendizajes e implicaciones}

Por nuestra parte, encuentro que hay varios aspectos de esta línea de pensamiento de Aristóteles de enorme relevancia, interés y utilidad de cara al impulso, fundamentación y desarrollo de la antropología 
práctica o de la praxis antropológica. Señalaré tres. Primero, la concepción de Aristóteles permite al científico social en general, y al antropólogo en particular, reconocer ante todo la pluralidad de saberes al llevar a cabo su práctica profesional (como investigador y docente, pero también en sus otros posibles roles de consultor, evaluador, capacitador, mediador, defensor, etc.) Este reconocimiento conlleva una actitud de clarificación y honestidad hacia sí mismo (y de humildad) -no somos nosotros solos quienes pensamos, ni tenemos un saber superior- así como una actitud de valoración del otro y de búsqueda de colaboración con él o ella, puesto que el científico social está objetivamente interesado en los otros saberes.

Segundo, ese reconocimiento posibilita, a su vez, establecer de forma explícita y fundamentada una relación de colaboración, que en otro lugar he planteado como de diálogo de saberes (Giménez 2012), esto es, posibilita participar conscientemente en una experiencia aplicada, implicada o pública, una experiencia de comunicación y debate franco y horizontal con los actores institucionales y sociales que están, como el propio antropólogo o antropóloga, involucrados en el programa, proyecto o iniciativa de que se trate. Se cuenta, en definitiva, con el conocimiento y saber de todos/as.

Tercero, la concepción plural de Aristóteles, permite además no presentar los términos de la relación teoría/práctica como algo dicotómico, sino plural -en la línea de lo señalado por Greenwood- desde el momento en que ya en el reino de la práctica aparecen dos saberes, la phrónesis y la techné. Esto es valioso pero no fácil. Zamora (2001) al tiempo que plantea lo original del planteamiento de Aristóteles, ha señalado la dificultad de diferenciación nítida entre phrónesis y techné:

"La gran originalidad del libro VI de la EN (Ética a Nicómaco) radica, precisamente, en una nueva concepción de las relaciones de la teoría y de la práctica. El estagirita delimita de forma sistemática el dominio de la praxis y del saber práctico (phrónesis) frente al dominio de la poiesis y del saber poíetico (techné). La dificultad de esta delimitación consiste en que tanto la praxis como la poiesis se presentan como una acción orientada a un fin, y los dos tipos de enunciados correspondientes, phrónesis y techné, como un saber capaz de orientar la acción hacia su correcta ejecución" (Zamora 2001: 38 ).

Por ello, los antropólogos y científicos sociales involucrados éticamente en la práctica deben esforzarse por indagar e identificar los aspectos de ambos saberes en los actores con quienes trabajan. Para concluir esta lectura de Aristóteles quisiera añadir una última idea sobre la superación de dicotomías reduccionistas: no sólo en el reino de la práctica hay pluralidad de saberes sino también en el mundo de la teoría. Por ejemplo, podemos distinguir las teorías que no buscan en principio conexión alguna con la práctica (lo cual encuentro perfectamente válido y legitimo) y las teorías que sí lo buscan o que incluso son generadas desde la praxis, lo cual no ha sido reconocido y legitimado por lo general dentro la corporación académica y, precisamente, de lo que se trata es de superar esa situación de dominio y empobrecimiento del quehacer científico e intelectual.

\section{Giambattista Vico y su Ciencia Nueva: el verum factum}

Tras Aristóteles, un segundo hito de tipo conceptual y metodológico es la concepción de Giambattista Vico acerca del verum factum, relevante tanto para el análisis de la relación entre teoría y práctica como para hacer propuestas para su articulación. Vico trató de fundamentar a mediados del siglo XVIII las ciencias históricas y sociales sobre bases sólidas y buscó el fundamento de una verdadera ciencia de la Humanidad, a la cual denominó Sciencia Nuova. La primera edición de esta obra fundamental es de 1725, luego se volvió a reeditar en 1730 y de esa segunda edición procede, sin modificaciones de fondo, la impresión de 1744, poco antes de su fallecimiento, en cuya traducción contemporánea nos basamos.

La aportación esencial de Vico en esa obra magna, por su carácter de núcleo epistemológico, es el verum factum. "Verum et factum reciprocantur seu convertuntur": o sea, lo verdadero y el hecho se convierten el uno en el otro y coinciden. Puede traducirse el verum factum bien como "es verdadero lo convertible en hecho" o también como "solo conocemos de verdad lo que hacemos". Refiriéndose a la 
propuesta de Vico, Abbagnano indica: "Dios y el hombre pueden conocer con verdad sólo lo que hacen: por esto las palabras verum y factum tienen en latín el mismo significado" (Abbagnano 1984: 349; cursivas mías). Para ubicar y comprender adecuadamente las aportaciones de Vico es necesario prestar atención a las formulaciones previas de otros filósofos y científicos de los comienzos de la modernidad, especialmente las teorías de conocimiento de tres pensadores: Francis Bacon, René Descartes y Godofredo Gottfried Leibniz.

\subsection{Influencias y debates}

Bacon concibió la ciencia como una actividad y saber orientado al dominio del hombre sobre la naturaleza (regnum hominis) y era plenamente consciente de sus aplicaciones prácticas. De hecho, quiso fundamentar lo que denominó una "ciencia activa". Su obra debía culminar en esa Ciencia Activa, esto es, una técnica dedicada a la aplicación a diversos campos de los hallazgos teóricos. Su obra principal será su Novum Organum, la cual es ante todo una lógica del procedimiento tecno-científico. De este "profeta filósofo de la técnica" como se le ha denominado (7), Vico llegará a la noción de verum facttum. Argumentando la influencia de Bacon sobre Vico, afirma Palerm: "De él (de Bacon) deriva Vico su teoría del verum-factum; o sea, que lo verdadero (el conocimiento cierto) es aquello que puede ser convertido en hecho (transformado en realidad)" (Palerm 1980).

La relación de Vico con la obra de Descartes no fue de complementariedad o desarrollo como con Bacon, sino de confrontación intelectual. Vico polemizó con Descartes sobre la pretensión de reducir todo conocimiento a la evidencia racional, pues para Vico ante la razón humana no solo hay verdad sino certidumbre. Vico está polemizando con Descartes puesto que considera que hay certezas que no pueden evidenciarse ni demostrarse, algo no asumible en el esquema cartesiano. Esta polémica ha sido valorada por diferentes analistas. Palerm afirma al respecto: "Vico también estuvo influido en forma negativa, o más bien polémica, por Descartes. En su obra se encuentra una oposición constante a la idea cartesiana de que la base del conocimiento cierto está dada por "las ideas claras y distintas". Para Vico esta concepción es errónea. La verdadera evidencia está constituida por la conversión de la verdad en el hecho. O sea, por la misma actividad humana, por el quehacer del hombre" (Palerm 1980: 50).

Abbagnano ve en esta posición de crítica hacia Descartes el punto de partida de las concepciones de Vico: "Descartes tuvo la pretensión de reducir todo conocimiento a la evidencia racional, esto es, a la razón necesaria y geométrica. Vico considera que esta pretensión es quimérica: hay certezas humanas fundamentales que no pueden evidenciarse ni demostrarse. Descartes redujo toda certeza válida a la necesidad de la razón geométrica. Vico defendió la autonomía y el valor de lo cierto frente a lo verdadero" (Abbagnano 1984: 349; cursivas mías).

Leibniz formuló la diferencia entre verdades de razón y verdades de hecho, distinción del todo necesaria en el esquema de Vico. Para ubicar adecuadamente esta distinción de Leibniz es preciso partir de otra previa: la que hace el filósofo de Leipzig entre orden y necesidad. Orden no significa necesidad, puesto que la necesidad sólo se presenta en el mundo de la lógica y no en el de la realidad, que es el que trata de ordenar el sujeto pensante. Dicho de forma directa: un orden real no es nunca necesario. A partir de ahí se sustenta que las verdades de razón son necesarias y no se refieren a la realidad. Leibniz califica esas verdades de razón (la verdad matemática, por ejemplo) como "idénticas" en el sentido de que no hacen más que repetir lo mismo sin decir nada nuevo. No hay en ellas, diríamos nosotros, historicidad alguna. Esas verdades de razón se basan, cuando son afirmativas, en el principio de identidad y, cuando son negativas, en el principio de contradicción.

Para Leibniz las verdades de hecho son marcadamente diferentes a las verdades de razón, pues son contingentes y se refieren a la realidad efectiva. No están basadas en los principios mencionados de identidad y contradicción, dado que su contrario sí es posible. Para Leibniz, las verdades de hecho -las correspondientes no al mundo de la lógica sino al real- están fundamentadas en el principio de razón suficiente: "nada se verifica sin una razón suficiente, esto es, sin que sea posible al que conozca suficientemente las cosas, dar una razón que baste para determinar por qué es así y no de otro modo" . Es importante entender que este principio de razón suficiente no es una causación necesariamente 
establecida, sino que se corresponde con un orden de concatenación en el cual las cosas, hechos o fenómenos que ocurren, quedan enlazados, sin que ello suponga una cadena causal necesaria. El principio de razón suficiente aporta inteligibilidad pero entendida ésta como algo que garantiza la libertad y contingencia de los sucesos reales.

\subsection{Planteamientos generales y distinciones conceptuales en Ciencia Nueva}

Si Francis Bacon, un siglo antes, tituló su obra Novum Organum, proponiendo un necesario nuevo método de investigación para el desarrollo de la ciencia, Vico publicó su propuesta bajo el título de Ciencia Nueva. Es significativo el subtítulo de su libro Principi d'una scienza nuova. Intorno alla comune natura delle natzión, es decir: Principios de ciencia nueva. En torno a la naturaleza común de las naciones. En ese subtitulo -vertebrado a partir de "naturaleza común" y "naciones"- está lo común y lo específico, las similitudes y las diferencias, la generalización y lo particular, una dialéctica tan esencial al pensamiento científico y a la antropología en particular. Vico aporta un ensayo de generalización a partir de la diversidad humana y asume la perspectiva comparada de la reflexión antropológica.

En la Ciencia Nueva, Vico se plantea y aborda las similitudes y diferencias entre las naciones y pueblos, la unidad y diversidad del género humano:

"Es necesario que haya en la naturaleza de las cosas humanas una lengua mental común a todas las naciones, la cual comprenda de manera uniforme la sustancia de cuanto tiene lugar en la vida humana sociable y la explique con tantas modificaciones diferentes cuantos aspectos diversos puedan tener las cosas: al modo como experimentamos en los proverbios, que son máximas de sabiduría popular, interpretadas sustancialmente de la misma forma por todas las naciones antiguas y modernas, aunque expresadas de modos muy diferentes" (Vico 1985: 109-110; cursivas mías).

"Una lengua mental común a todas las naciones": Vico se está adelantando a la formulación de la premisa de la unidad psíquica del género humano que plantearan los evolucionistas del siglo XIX, fundadores de la antropología social como disciplina científica. Por otro lado, esta idea de la "lengua mental común" supone un planteamiento universalista en el que encuadrar el análisis y explicación de la diversidad. En efecto, esa lengua mental común comprende "de manera uniforme" la "sustancia" de la "vida humana sociable" y, al tiempo, la debe explicar "con tantas modificaciones diferentes cuantos aspectos diversos puedan tener las cosas". Se trata de un planteamiento explícito de unidad en la diversidad -cuestión central en la antropología- y que Vico ejemplifica con esas "máximas de sabiduría popular" que son los proverbios, interpretados de la misma forma por gentes de diversos pueblos y naciones pero expresados de modos muy diferentes. "Las tradiciones populares deben haber tenido un elemento público de verdad, de ahí nacerán y se conservaran en pueblos enteros durante largos intervalos de tiempo" (Vico 1985: 107).

Las antinomias que plantea el filósofo napolitano son tres. En primer lugar, la oposición verdadero/cierto, o lo que es lo mismo verdad/certidumbre, como dos posibilidades con respecto a la realidad. En segundo lugar, la antinomia ciencia/conciencia como formas de pensamiento que residen en la mente humana: la primera sólo en el caso de filósofos y científicos, la segunda en el caso de todos los seres humanos. En tercer lugar, el dualismo intelecto/voluntad, correspondiendo al primero de ello lo relativo al desarrollo de la ciencia y lo verdadero, y a la segunda lo referente al desarrollo de la conciencia y lo cierto.

\section{Tabla 2}

\section{Esquema de las categorías de Vico en Scienza Nuova}




\begin{tabular}{|c|c|c|}
\hline $\begin{array}{c}\text { Posibilidades ante lo } \\
\text { real }\end{array}$ & $\begin{array}{l}\text { La verdad } \\
\text { Lo verdadero }\end{array}$ & $\begin{array}{l}\text { La certidumbre } \\
\text { Lo cierto }\end{array}$ \\
\hline $\begin{array}{l}\text { Fuente del } \\
\text { conocimiento }\end{array}$ & La razón & El libre albedrio \\
\hline $\begin{array}{l}\text { Formas de } \\
\text { pensamiento }\end{array}$ & $\begin{array}{c}\text { Ciencia } \\
\begin{array}{c}\text { (propio de filóso fos y } \\
\text { cientificos) }\end{array}\end{array}$ & $\begin{array}{l}\text { Conciencia } \\
\text { (en todos los seres } \\
\text { humanos) }\end{array}$ \\
\hline Facultades humanas & Intelecto & Voluntad \\
\hline
\end{tabular}

Fuente: elaboración propia a partir de G. Vico, Ciencia Nueva

Las concepciones de Leibniz sobre necesidad y orden y sobre verdades de razón y verdades de hecho parecen imprescindibles para el paso que dará Vico en su propuesta de Ciencia Nueva a partir del verum factum. En efecto, una idea central en Vico es su distinción entre verdad y certidumbre y entre ciencia y conciencia. "Los hombres que no saben la verdad de las cosas procuran atenerse a lo cierto, puesto que, al no poder satisfacer el intelecto con la ciencia, al menos la voluntad descansa sobre la conciencia" (Vico 1985: 105; cursivas mías). Y también: "La filosofía contempla la razón, de donde procede la ciencia de lo verdadero; la filología estudia la autoridad del albedrío humano, de donde procede la conciencia de lo cierto" (Vico 1985; cursivas mías). Al leer "filología", según la época y el proyecto viquiano, podemos hoy día entender ciencias humanas y sociales.

En el postulado viquiano acerca del valor de lo cierto frente a lo verdadero se expresa un principio clave en toda experiencia de trabajo científico aplicado: que el científico aplicado experimenta y conoce vivencias y procesos que no son reducibles al conocimiento teórico, si bien pueden alimentar procesos teóricos. Cuando el científico social y, en su caso, el antropólogo o etnógrafo participa, por ejemplo, de un determinado proyecto social de desarrollo comunitario, trabaja con cosas ciertas, pero no verdaderas.

\subsection{La propuesta metodológica de Vico}

¿Y cómo propone Vico establecer las base de esa Ciencia Nueva? ¿Qué vía o método propone? Palerm no deja de sorprenderse de lo innovador del planteamiento metodológico de Vico y trae a colación un párrafo clave de Scienza Nuova donde se expresa el punto de partida de la propuesta epistemológica y metodológica de Vico: "La metodología que utiliza Vico para proceder en su estudio de la ciencia nueva (...) parte de una idea sorprendente del conocimiento posible" (Palerm 1980).

Ese párrafo de Vico que trae Palerm a colación es el siguiente:

"El mundo civil (que para Vico es el mundo histórico y social) es ciertamente la obra del hombre, y en consecuencia se puede y se debe descubrir los principios en las modificaciones de su inteligencia misma. Quien reflexione sobre esta cuestión no podrá dejar de sorprenderse de que los filósofos que han emprendido el estudio del mundo físico -que sólo Dios que es el autor puede conocer- hayan desdeñado el mundo civil de las naciones, que los hombres pueden conocer porque lo han hecho. Esto proviene de una enfermedad de nuestro espíritu; enterrado en su envoltura corporal se ve obligado a considerar las cosas materiales, mientras le cuesta un gran esfuerzo comprenderse a sí 
mismo. De la misma manera el ojo que ve todos los objetos necesita sin embargo de un espejo para verse a sí mismo" (Palerm 1980: 50-51; cursivas mías).

En efecto, vemos aquí un punto de partida de extraordinario interés: como el hombre hace el mundo puede por ello conocerlo. Esto es, en el mundo social, tal y como es, se expresa lo humano, porque el mundo social es su producto, porque los individuos son sus artífices. Efectivamente, es digno de asombro que estos planteamientos se hicieran a mediados del XVIII, más de un siglo antes de la configuración o formalización de las ciencias sociales como tales.

Entre las frases que he enfatizado en el texto de Vico figura su observación de cómo los humanos "enterrados en su envoltura corporal"- se han dedicado más a la comprensión del mundo natural (ciencias naturales) que a su propio mundo. Hay aquí un antecedente de algunos de los elementos planteados en la concepción de Max Weber de que ciencias naturales y sociales comparten la "explicación causal" pero sólo las segundas disponen de la "comprensión intuitiva" (verstehen) precisamente porque esta última está basada en que el sujeto (los humanos) y el objeto (las realidades sociales) son de la misma naturaleza.

Considerado el punto de partida, entremos más en la vía metodológica de Vico. Vico se plantea cómo puede conocerse este mundo que ha sido creado por el hombre y postula que hay dos instrumentos principales para ello. Por una parte, los métodos que los científicos naturales están empleando ya con tanto éxito (una vez más la misma idea de Weber de que la explicación causal es algo común a todas las ciencias y científicos). Por otra parte, Vico propone una segunda vía, que no es sino el verum factum.

En palabras de Palerm:

"El segundo instrumento metodológico se basa en su teoría del verum-factum, o sea, que lo verdadero (es decir el conocimiento cierto) es aquello que puede ser convertido en hecho (es decir, transformado en realidad). En otras palabras, el desarrollo de la historia es racional porque así se ha producido, así ha ocurrido. Más importante todavía, en último análisis, la única prueba posible de nuestro conocimiento consiste en llevarlo a la práctica. El quehacer del hombre en el mundo que está siendo constantemente creado por su actividad (el mundo civil en la terminología viquiana) está incesantemente probando la verdad convirtiéndola en hecho. Hegel tomará está idea y la expresará un siglo más tarde diciendo que todo lo racional es real. Marx hará lo mismo, escribiendo los hombres hacen su propia historia pero en condiciones determinadas por distintos factores" (Palerm 1980: 50).

Por nuestra parte, quisiera resaltar que aquí figura otro precedente relevante de la discusión sobre la práctica como instancia de verificación o validación del conocimiento, tema al que volveremos más adelante y en los próximos ensayos, y que -como expresaba en la Introducción- ubico como el tercer momento de las relaciones entre teoría y práctica (8).

"Los hombres no saben la verdad de las cosas, procuran atenerse a lo cierto, puesto que, al no poder satisfacer el intelecto con la ciencia, al menos la voluntad descansa sobre la conciencia" (Vico 1985: 105). Vico distingue la ciencia de lo verdadero de la ciencia de lo cierto, homologando la primera a la filosofía y la segunda a la filología: "La filosofía contempla la razón, de donde procede la ciencia de lo verdadero, la filología estudia la autoridad del albedrío humano, de donde procede la ciencia de lo cierto" (Vico 1985: 105). Fijémonos en la fuente de pensamiento en la que se basa cada una de ellas: la filosofía en la razón (verdades de razón que diría Leibniz) y la filología en "la autoridad del albedrío humano". Se dibuja aquí una nueva distinción -la de razón/autoridad- paralela a las anteriores de verdadero/cierto y ciencia/conciencia. Ahora bien, Vico no está proponiendo el "criterio de autoridad" en el sentido de "esto es cierto porque lo dijo tal gran persona". La lectura que hago de ello es que Vico propone basar la filología, como ciencia de lo cierto, en la experiencia humana acumulada. Los hombres por su vida, su práctica, su experiencia, van disponiendo de un saber $y$, libremente, con su capacidad de valorar, indagar, etc., pueden fundar ese otro conocimiento que no es el de las verdades de razón sino el de las verdades de hecho, volviendo a utilizar la distinción de Leibniz. Si esto es así, ello conecta a Vico, en 
parte, con el Aristóteles de los varios saberes, así como, también en parte, con el pensamiento que analizaremos más adelante de John Dewey acerca del valor de la experiencia como fuente de conocimiento.

\subsection{Otras reflexiones relevantes}

Una vez contextualizada la obra de Vico y expuesto lo esencial de sus planteamientos conceptuales y metodológicos, consideremos algunos otros aspectos de su pensamiento especialmente relevantes para la discusión sobre teoría y práctica. Cinco temáticas nos parecen de considerable interés a este respecto: las que tienen que ver, respectivamente, con el libre albedrío y el sentido común, su concepción del campo de las humanidades y estudio de la realidad social, la correspondencia que establece en sabiduría y virtud, lo estratégico de las categorías de necesidad y utilidad y la historicidad con relación al verum factum.

\subsubsection{Libre albedrío y sentido común}

Vico razona sobre el sentido común, algo que luego será clave en la obra de Gramsci: "El albedrío humano, por su naturaleza muy incierto, se fija y determina con el sentido común de los hombres en torno a las necesidades o utilidades humanas, que son las dos fuentes del derecho natural de las gentes" (Vico 1985: 106). Sostiene Vico que dos rasgos de ese sentido común son, primero, la ausencia de reflexión y, segunda, su carácter colectivo o compartido: "El sentido común es un juicio sin reflexión alguna, comúnmente sentido por todo un orden, por todo un pueblo, por toda una nación o por todo el género humano" (Vico 1985).

Esa línea de interpretación de cómo Vico postula "la autoridad del libre albedrío" parece en consonancia con estos otros axiomas expresando en la Ciencia Nueva: "El albedrío humano, por su naturaleza muy incierto, se fija y determina con el sentido común de los hombres en torno a las necesidades o utilidades humanas, que son las dos fuentes del derecho natural de las gentes" (Vico 1985: 106). La referencia y relevancia del sentido común conecta a Vico con otros pensadores que traeremos a colación en esta búsqueda de bases donde fundamentar una articulación de teoría y práctica, y especialmente en este punto las aportaciones de Antonio Gramsci.

Continúa Vico sobre el sentido común: "El sentido común es un juicio sin reflexión alguna, comúnmente sentido por todo un orden, por todo un pueblo, por toda una nación, por todo un género humano. Este axioma unido a la siguiente definición nos determinará una nueva arte crítica referida a los autores de las naciones, en los cuales debieron transcurrir bastante más de mil años para que aparezcan los escritores, de los que hasta ahora se ha ocupado la crítica" (Vico 1985: 106).

\subsubsection{La Filología viquiana: campo de las Humanidades y Ciencias Sociales}

Respecto la filología, la descripción de sus protagonistas y de sus objetos de estudio que hace Vico la asimila a lo que entendemos desde mediados del siglo XIX como humanidades y/o ciencias humanas o sociales. El axioma que hemos citado continúa así: "La segunda parte de este axioma define como filólogos a todos los gramáticos, historiadores, críticos, que se ocupan del conocimiento de las lenguas y de los hechos de los pueblos, tanto internos, como son las costumbres y las leyes, como externos, como son las guerras, las paces, las alianzas, los viajes, el comercio“ (Vico 1985: 105). Las lenguas, los procesos históricos y los pueblos, tanto en su configuración interna como en sus relaciones exteriores: así enumera el objeto de la "filología", en la cual no va haber ciencia de lo verdadero pero sí ciencia de los cierto, no va a haber verdades pero sí certidumbres.

Tras ello, Vico muestra críticamente cómo en la historia del pensamiento no ha habido la suficiente complementariedad entre ambas forma de conocimiento: "Este mismo axioma demuestra que han faltado en la mitad, tanto los filósofos que no verificaron sus razones con la autoridad de los filólogos, cuanto los filólogos que no se preocuparon de apoyar su autoridad con la razón de los filósofos; cosa que si hubiese sido hecha, habría sido muy útil a las repúblicas y nos habría prevenido en la reflexión de esta ciencia" (Vico 1985: 105). 
Las consecuencias de la falta de entendimiento y colaboración entre los saberes no son solo epistemológicas, sino también prácticas y políticas.

\subsubsection{De nuevo ciencia y virtud}

En Vico se vuelve a expresar la idea de la Grecia clásica de la conveniente correspondencia entre filosofía y ciencia, por un lado, y por el otro de virtud y sabiduría. Señalamos anteriormente cómo ese nexo quedó roto cuando la ciencia moderna fundamentó la separación radical del sujeto y el mundo, de lo subjetivo y lo objetivo, una línea de pensamiento y método que se convirtió en hegemónica en el siglo $\mathrm{XVI}$, con la influencia sobre todo de Descartes y el racionalismo.

Esa conexión entre teoría y práctica, entre razón y sabiduría, entre explicación y uso, es expresada por el filósofo napolitano en sentencias como la siguiente: "La equidad natural de la razón humana en su total despliegue constituye la práctica de la sabiduría en las acciones útiles, puesto que 'sabiduría', en toda su amplitud, no es otra cosa que la ciencia de hacer uso de las cosas de acuerdo con su naturaleza" (Vico 1985: 140).

\subsubsection{De lo necesario y lo útil a la prioridad para el pensamiento no filosófico}

Y ¿cómo opera esta ciencia de los cierto, esta ciencia de las cosas humanas, de la vida sociable? El plan para la Ciencia Nueva que traza Vico es analizar la historia de las ideas de los seres humanos acerca de las mencionadas "dos fuentes del derecho natural de los pueblos": la necesidad y la utilidad. "Para intentar encontrar dicha naturaleza de las cosas humanas esta ciencia procede de un riguroso análisis de los pensamientos humanos en torno a las necesidad o utilidad humanas de la vida social, que son las dos fuentes perennes del derecho natural de los pueblos tal y como en los Axiomas se ha señalado" (Vico 1985: 148-149; cursivas mías). Con ello se identifican dos aspectos que serán luego cruciales en el desarrollo de las ciencias sociales.

Por un lado, el estudios de las necesidades humanas: pensemos en los economistas desde la llustración y la ciencia económica posterior y los balances entre necesidades y recursos, o en la relevancia definidora de la satisfacción de las necesidades en los estudios campesinos substantivistas con Chayanov a la cabeza, o en la teoría de las necesidades en el funcionalismo de Malinowski, o en psicología la pirámide de las necesidades de Maslow, o las sistematizaciones sobre necesidades fundamentales y satisfactores en Max Neef, etc.

Por otro lado, las categorías de utilidad y lo útil, que nos llevan directamente al estudio de los descubrimientos e innovaciones desde Morgan para acá, a la categoría del valor de uso y su contraposición a valor de cambio en Marx, a las filosofía utilitarista y el pragmatismo, o directamente a la cuestión del uso y carácter práctico y útil de las cosas humanas y, entre ellas, de la teoría.

Vico deducirá un importante corolario de esa característica central de la "filología" o ciencia social como es el "riguroso análisis de los pensamientos humanos": que ello previo o primero con respecto a la mismísima filosofía: "De ahí que por este otro importante aspecto suyo, esta ciencia es una historia de las ideas humanas, de la cual parece que debe proceder la metafísica de la mente humana: ésta, reina de las ciencias, de acuerdo con el axioma, las ciencias deben comenzar de donde comenzó en materia, comenzó desde el primer momento que los hombres comenzaron a pensar humanamente, y no desde cuando los filósofos comenzaron a reflexionar sobre las ideas humanas (como recientemente ha sacado a la luz un librito erudito y docto el título Historia de las ideas, que alcanza hasta las últimas controversias que han protagonizado los dos principales ingenieros de esta época Leibniz y Newton)" (Vico 1985: 148149; cursivas mías).

Dicho de manera más directa: Vico concede la primeridad -respecto a la filosofía- al pensamiento humano en general, al pensamiento humanos sobre lo necesario y lo útil. $\mathrm{O}$, por utilizar las categorías de las últimas lecciones de Carmen Viqueira (2004) en su seminario sobre el método científico, primero fue el "pensamiento productivo" y luego el "pensamiento científico". 


\subsubsection{Historicidad y verum factum}

La historicidad de la realidad humana queda patente en postulados de Vico como el siguiente: "La naturaleza de las cosas no es sino que nacen en ciertos tiempos y bajo ciertas circunstancias, las cuales siempre que son las mismas, de ellas mismas y no otras cosas nacen" (Vico 1985: 107).

Vico distinguió la historia ideal y la historia real, la historia única y común y las historias particulares: "Esta ciencia describe al mismo tiempo una historia ideal y eterna conforme a la cual transcurren en el tiempo las historias de todas las nociones en sus nacimientos, progresos, equilibrios, decadencias $y$ finales" (Vico 1985: 149; cursivas mías). Y con ello vuelve al principio central del verum factum:

"Así nos anticipamos a afirmar que quien conoce esta ciencia se relata así mismo esta historia ideal y eterna, porque -al haber sido este mundo de naciones hecho por los hombres (lo que constituye el principio no cuestionado que se ha afirmado anteriormente), y debiéndose por lo tanto encontrar el modo dentro de las modificaciones de nuestra misma mente humana- mediante la prueba debido, debe, deberá él mismo se la hace ya que, cuando se da el caso de que quien hace las cosas es el mismo que las cuenta, no puede ser más cierta la historia. Así, esta ciencia procede del mimo modo que la geometría, la cual, mientras construye o medita sobre sus elementos, ella misma produce el mundo de las dimensiones; peor con tanta realidad cuando es mayor la realidad de las leyes referentes a las acciones de los hombres, que la tienen los puntos, las líneas, las superficies y las figuras. $Y$ esto mismo constituye el argumento de que tales pruebas son una especie divina y que deben, lector, proporcionarte un divino placer, puesto que en Dios el conocer y el hacer son la misma cosa" (Vico 1985: 149; cursivas mías).

La influencia de Vico ha sido amplia e intensa en pensadores posteriores. A los efectos de nuestra indagación sobre teoría y práctica nos interesan especialmente las comparaciones que se han hecho entre Vico y Marx. "En algunos momentos de la Ciencia Nueva esta teoría se acerca a la idea de la praxis que formuló Marx; Vico usa, incluso, el término práctica civil o social" (Palerm 1982: 25-26; cursivas mías). Dejemos aquí la reflexión sobre Vico en su relación con Marx pues, antes de "saltar" a él, hay que hacer un alto de enorme interés abordando la perspectiva y aportación de Kant con relación a la relación a la teoría y la práctica.

\section{Immanuel Kant: teoría y práctica en su disertación de 1793}

El ensayo de Kant En torno al tópico: "tal vez eso sea correcto en teoría pero no sirve para la práctica", de 1793, es un texto corto, concretamente 58 páginas en la edición en castellano de 2006 . Se trata de un texto de defensa no solo argumentada sino apasionada de la teoría y de su valor práctico. El texto se ubica en el tercer y último periodo de las obras de Kant o "periodo crítico", correspondiente a sus obras principales, etapa que se inicia con la publicación en 1781 de la Crítica de la Razón Pura, después de diez años de reflexiones y elaboraciones en torno a las diversas temáticas que abordó en esa obra clave en la historia del pensamiento. Luego vendría la Critica de la Razón Práctica (1787) y luego la Crítica del Juicio (1790).

Tras ellas vendrían otras obras claves, entre las que resaltaré dos de ellas por su especial interés antropológico y por su conexión a la temática de este ensayo. Me refiero, por un lado, a La metafísica de las costumbres (1797) -con una primera parte dedicada a los "Fundamentos metafísicos de la doctrina del derecho" y una segunda parte donde Kant aborda los "Fundamentos metafísicos de la doctrina de la virtud“; y, por otra parte, la Antropología desde el punto de vista pragmático (1798) en cuyo prólogo Kant distingue entre la "antropología fisiológica" (dedicada a determinar la naturaleza del ser humano) y la "antropología pragmática" (que estudia el ser humano tal y como se hace a sí mismo partir de su libre voluntad).

Durante ese "periodo crítico" de obras fundamentales como las mencionadas, el filósofo de Königsberg 
fue publicando numerosos e incisivos artículos, disertaciones, juicios críticos, opúsculos o aclaraciones sobre diversos temas como, entre otros, el cosmopolitismo, el concepto de raza humana, lo que significa orientarse en el pensar, el fanatismo, la posibilidad de paz perpetua, el tono noble de la filosofía, el presunto derecho a mentir por amor o el poder del sentimiento. En ese conjunto de obras, Kant desarrolló y aplicó su pensamiento a temas concretos y de actualidad, recensionó y prologó a otros autores, y debatió con otros intelectuales. Entre ese conjunto de textos hay que ubicar el de 1793, En torno al tópico: "tal vez eso sea correcto en teoría pero no sirve para la práctica".

A continuación voy a centrarme en este ensayo especialmente rico para la discusión sobre la relación/articulación entre teoría y práctica. Este opúsculo kantiano se compone de tres apartados, cada uno de los cuales aborda la relación entre teoría y práctica con respecto a una temática clave y en cada uno de los cuales Kant debate con un autor diferente. Estos tres apartados son los siguientes: I. "Acerca de la relación entre teoría y práctica en la Moral (en respuesta a unas cuantas objeciones del profesor Grave)"; II. "De la relación entre teoría y práctica en el Derecho Político (contra Hobbes)"; y III. "De la relación entre teoría y práctica en el Derecho Internacional, considerada con propósitos filantrópicos universales, esto es, cosmopolitas (contra Moses Mendelssohn)".

Al explicar el propio Kant el plan de la obra ya deja claro cómo la contestación a quienes reniegan del valor práctico de las teorías está en la génesis y motivación de fondo del texto: "Dividiré este tratado siguiendo los tres distintos puntos de vista conforme a los cuales suele juzgar su objeto ese hombre de honor que tan atrevidamente reniega de teorías y sistemas; siguiendo pues una triple dualidad: 1) como hombre privado, pero con ocupaciones y responsabilidades (Geschäftsmann); 2) como hombre político; 3) como cosmopolita (o ciudadano de mundo). Estas tres personas coinciden en arremeter contra el académico, que elabora teorías para todos ellos y en su beneficio; y como ellos se figuran que entienden más del asunto, le indican que se vaya a la escuela (illa se iactet in aula!), como a un pedante que, perdido para la práctica, no hace sino cerrarles el paso de su experimentada sabiduría“ (Kant 2006: 6-7; cursivas mías) (9).

\subsection{La noción de teoría en Kant}

El ensayo, comienza con un contundente párrafo definidor de teoría y práctica: "Se denomina teoría incluso a un conjunto de reglas prácticas, siempre que tales reglas sean pensadas como principios, con cierta universalidad, y, por tanto, siempre que hayan sido abstraídas de la multitud de condiciones que concurren necesariamente en su aplicación. Por el contrario, no se llama práctica a cualquier manipulación, sino sólo a aquella realización de un fin que sea pensada como el cumplimiento de ciertos principios representados con universalidad" (Kant 2006: 3; cursivas mías).

Centrémonos primero en la concepción kantiana de teoría, la que se define a partir de la reglas, esto es, como "un conjunto de reglas prácticas", siendo a nuestro parecer extremadamente relevante que en la mismísima sustancia de lo que es teoría aparezca está presente ya lo práctico, y aparece como atributo de esas reglas definitorias de lo teórico, es decir se trata de reglas que se pueden aplicar, sirven para algo, son útiles. Así pues, la misma concepción de teoría conlleva la práctica; y como vemos ocurre algo semejante en la concepción kantiana de práctica, la que se define a partir de la realización de un fin, pero pensada con unos determinados principios representados con universalidad, es decir abstraídos de la realidad, lo cual es marca de lo teórico. Esta remitencia bidireccional que establece Kant entre teoría y práctica, y en la cual radica buena parte de la defensa del valor de la teoría (pues lleva la práctica en su propia naturaleza) recuerda sobremanera la unidad de los contrarios del ying/yang chino.

Glosaremos la concepción kantiana de teoría indicando que: no cualquier conjunto de reglas constituye una teoría sino solo aquellas reglas con dos atributos o cualidades:

1) Que constituyan principios universales o cuasi universales.

La afirmación de Kant de que es preciso que dichas reglas "sean pensadas como principios, con cierta universalidad" remite lo teórico al campo de los principios y éstos al universalismo, a los universales, a lo válido en cualquier tiempo y lugar, si bien matiza "con cierta universalidad" (énfasis añadido) situándonos 
no ante un universalismo absoluto sino ante uno de cierto grado o extensión. Volvemos aquí ante la dicotomía universal/particular y a la premisa aristotélica de que no hay ciencia de lo particular o su distinción de que si la theoría se sitúa en lo eterno, fijo, abstracto o universal, la techné y la phrónesis se ubican ambas en lo perecedero, cambiante, concreto o particular (10).

2) Que sean productos de la abstracción.

Inmediatamente después de formular que la teoría es un conjunto de reglas y que éstas son principios con cierta universalidad, Kant añade "y, por lo tanto, siempre que hayan sido abstraídas de la multitud de condiciones que concurren necesariamente en su aplicación". El "por lo tanto" está señalando un corolario o necesidad. Esas reglas o principio con vocación de universalidad, requieren necesariamente haber sido abstraídos, sacados del mar de lo concreto. La formulación kantiana, "abstraídas de la multitud de condiciones que concurren necesariamente en su aplicación", remite a la pluralidad y casuística de lo concreto, pero tiene para nosotros -como antropólogos aplicados- un especial interés al mencionar precisamente la aplicación.

En esta conceptualización de la teoría, Kant no solo remite a lo práctico (reglas prácticas) sino también a lo aplicado. En la misma concepción de lo teórico ya está incorporado el proceso de su aplicación, un proceso en el que concurren multitud de condiciones. No nos interesa ahora fijar la atención de nuevo hacia la necesidad de abstraer a partir de esa multiplicidad, sino el hecho de que el propio proceso de aplicación de la teoría es necesariamente concreto, particular, singular, casuístico. Volveremos sobre este aporte kantiano cuando analicemos el proceso de aplicación (lo que formulamos como Momento II de la relación/articulación entre teoría y práctica), así como también cuando hayamos de considerar cómo de la aplicación y de la praxis (o práctica fundamentada en teoría) podemos generar nueva teoría (Momento IV).

Siguiendo la concepción kantiana de teoría podemos sintetizar que, a la hora de articular teoría y práctica, deberemos tener en cuenta: a) que de lo que disponemos para su aplicación -la teoría- es de un conjuntos de reglas prácticas y operativas en el mundo; b) que son principios formulados con vocación de cierta universalidad (el campo de aplicación de la regla); c) que son abstracciones, esto es, proposiciones o formulaciones que no se ajustan a este o aquel caso o situación concreta; d) que para ajustarse es preciso un proceso de aplicación, o de concreción de esa teoría (11).

\subsection{La noción kantiana de práctica}

La concepción kantiana de práctica va directamente ligada a la de teoría: "Por el contrario, no se llama práctica a cualquier manipulación, sino sólo a aquella realización de un fin que sea pensada como el cumplimiento de ciertos principios representados con universalidad" (Kant 2006: 3; cursivas mías).

Hay tres partes y rasgos en esta concepción kantiana de la práctica que conviene comentar. Primero, la afirmación radical de que "no se llama práctica a cualquier manipulación". La primera aportación de Kant es establecer lo que no es "práctica". Está distinguiendo entre "cualquier manipulación" y determinadas manipulaciones que sí constituyen una práctica. Hay que apreciar aquí que se evite precisamente una concepción tan amplia de práctica que resulte inútil. En esta Disertación sobre teoría y práctica que analizamos, Kant parte de una concepción acotada, estricta, de práctica. Otro aspecto a resaltar en esta primera idea es que la práctica es un tipo de manipulación, no cualquier manipulación sino aquella que reúna características que en seguida se plantean en la definición. El término manipulación es interesante, pues nos sitúa no solo ante un cambio sin más sino ante una transformación de algo, y por lo tanto ante un manejo u operación motivada por algo, impulsada por una pretensión, pero esto nos mete ya en el corazón del concepto.

Segundo, Kant acota la categoría de práctica como la "realización de un fin", lo cual implica -en la lectura que hacemos del texto de Kant- la idea de proceso, la relación medios/fines, y sobre todo la idea de intencionalidad y voluntad. Al constituir la realización de un fin se está generando un tránsito entre una situación en la que ese fin o meta no está presente y otra en la que ya ha sido conseguido (precisamente mediante la práctica). En cierta forma, la práctica aparece como medio que conduce a un fin, o al menos 
está implícita la idea de que en la práctica se proveen los medios que conducen a la realización del objetivo o meta. Además, ello implica un sentido u orientación de la manipulación o acción trasformadora, una intención de realizar ese fin. Y, en definitiva, todo ello conlleva una voluntad, una determinación de querer realizar un determinado fin.

Tercero, el gran filósofo ilustrado indica que toda práctica es "pensada como el cumplimiento de ciertos principios representados con universalidad". Aquí no se especifica si "es pensada" por el propio actor de la práctica o por el teórico externo a ella, el texto parece referirse a lo primero, pero ambas posibilidades son de interés. Encuentro de especial relevancia la afirmación de que la práctica, toda práctica (pues estamos definiendo) "es pensada". Dicho de otra manera, en toda práctica hay concepción de ella, y esto abre todo un campo de exploración de interés como es lo relativo a qué pensamiento y qué conocimiento subyace en cada práctica (algo que retomaremos con Marx, Dewey, Gramsci...). Pero sigamos, pues Kant especifica de qué manera, desde dónde, es pensada la práctica: "como el cumplimiento de ciertos principios representados con universalidad". Esta posición conecta el concepto de práctica con el campo de los principios y la dimensión de lo universal. Ver las prácticas como realizaciones de fines, y éstas como pensadas como cumplimientos de determinados principios, tiene la virtud (heurísticamente útil) de acotar el terreno: solo son prácticas las realizaciones de determinados fines que conlleven el cumplimiento de determinados principios.

Encuentro también valiosa la conexión kantiana entre práctica y principios por cuanto liga determinadas acciones transformadoras de un sujeto o grupo a los principios que lo guían, mueven, inspiran o dan sentido. En toda práctica no solo hay concepción y pensamiento sino también finalidades y principios. $Y$ esto último nos sitúa en el campo del análisis de los valores, preferencias, prioridades y objetivos. Kant precisa que se trata de "ciertos principios representados con universalidad". Tal y como lo formula, parece que no vale cualquier principio que inspire o motive una práctica, sino solo aquellos que son representados con universalidad (12).

\subsection{El pasaje de la teoría a la práctica}

Una vez definidas la teoría y la práctica, Kant aborda la transición de la primera a la segunda:

"Por muy completa que sea la teoría, salta a la vista que entre la teoría y la práctica se requiere aún un término medio como enlace para el tránsito de la una hacia la otra; pues al concepto del entendimiento, concepto que contiene la regla, se tiene que añadir un acto de la facultad de juzgar por medio del cual el práctico distingue si algo cae bajo la regla o no. Y como, por otra parte, para la facultad de juzgar no siempre se pueden dar reglas conforme las cuales tenga que regirse en la subsunción (porque se daría un regresum in infinitum), puede haber teóricos que nunca en su vida serán capaces de convertirse en prácticos porque carecen de la facultad de juzgar: tal es el caso, por ejemplo, de médicos o juristas, que han hecho bien sus estudios, pero no saben cómo han de conducirse a la hora de dar consejo" (Kant 2006: 3-4; cursivas mías).

De este pasaje quisiera retener otros tres aspectos para nuestro razonamiento, Primero, que en el pasaje de la teoría a la práctica hay una operación que no es intelectiva sino valorativa, axiológica. En el campo de la ciencia social aplicada, en el campo de la antropología aplicada, los valores, las ideologías, entran ya plenamente. No es que no estén presentes en la elaboración teórica fundamental o "pura" (el ámbito de la ciencia social "básica") sino que cuando nos situamos en la esfera de la aplicación del conocimiento, en el ámbito del conocimiento aplicado, entonces esas categorías de juicio, de valor, son centrales, directas, dadoras plenamente de sentido a la acción práctica.

En segundo lugar, Kant observa con acierto que "la teoría hace abstracción de toda una serie de condiciones que determinan su aplicación" y, en efecto, para fundamentar adecuadamente la ciencia social aplicada -y dentro de ello la antropología como caso particular- es preciso recordar que si la teorización se mueve por definición en el campo de la abstracción (elaborando modelos, tipologías, sintetizando, etc.), la aplicación deambula en el campo de la concreción. Dicho de otra manera, el científico social aplicado deberá, por una parte, tener en cuenta con todo detalle lo que Willingen (1985) 
denomina el "contexto de la aplicación" y, por otra parte, disponer de una serie de habilidades e instrumentos propios del dominio de la práctica (comunicabilidad entre profesional y resto de actores; labor de traducción constante entre la experiencia y el lenguaje en la práctica y, por otro lado, los conocimientos y lenguajes científicos; el ritmo distintivo del trabajo práctico o aplicado respecto al existente en las labores teóricas; la flexibilidad y los replanteamientos en el quehacer práctico, etc.).

Tercero, que la diferencia entre el sujeto teórico y el sujeto práctico no radica en que uno haga teoría y el otro no, sino que el primero se queda en ello y el segundo -dotado de una "capacidad de juzgar" como afirma Kant (y yo añadiría: con una voluntad de hacerlo)- no se queda en la teoría sino que realiza todas o algunas de las siguientes posibilidades: a) orienta la investigación básica hacia lo práctico y/o lo público, en su totalidad o al menos en parte; b) promueve vías de investigación acción participativa; c) "desciende" (o "asciende") al terreno de lo práctico y lo aplicado; y d) genera conocimiento y teoría desde la propia práctica.

\subsection{Casos en los que la teoría no vale en la práctica}

En su análisis pormenorizado de este texto de Kant, señala Sartori:

"Kant no sostiene que en todos los casos lo que es justo (13) en teoría deba también ser justo en la práctica. En efecto, hay dos casos en los cuales la teoría no vale en la práctica: 1) cuando la teoría es errónea o imperfecta (pero entonces, observa Kant, "no dependía de la teoría si ella valía poco para la práctica, sino del hecho de que no había bastante en dicha teoría"), 2) cuando tenemos una teoría que no "se refiere a objetos de intuición" (nosotros diríamos: que no tienen fundamento empírico), sino en cambio una "teoría en la cual tales objetos están representados sólo por conceptos (por ejemplo, los objetos de la matemática y la filosofía), y estos últimos pueden ser pensados perfectamente y en pleno acuerdo con la razón, y sin embargo no estar dados (debe entenderse: dados por medio de la experiencia) y ser ideas vacías; que en la práctica no tendrían ningún uso" (Sartori 1995: 89).

$Y$, en efecto, las reflexiones de Kant sobre los posibles casos en los que la teoría no vale o parece no valer en la práctica son de enorme interés para lo que nos atañe, ya que nos sitúa ante la cuestión de cuándo sí vale y porqué. Merece efectivamente la pena ahondar en las dos razones expuestas por Kant sobre la teoría que puede no valer en la práctica.

Respecto al posible carácter erróneo o imperfecto de determinada teoría consideramos pertinente -desde la práctica contemporánea- la observación kantiana de que esa característica influye en la aplicabilidad práctica, y que desde luego es muy conveniente apoyarse en teorías sólidas, y validadas. Ahora bien, discrepo de la proposición en su esencia: que una teoría no vale cuando es errónea o imperfecta. Mi discrepancia no emana principalmente de la concepción actual sobre la verdad (Popper, etc.) que nos llevaría a dudar del trazado de una frontera clara entre teorías verdaderas y erróneas, perfectas e imperfectas, sino por una posibilidad y realidad que considero esenciales en la discusión: que es posible aplicar una teoría errónea y que, de hecho, así se hace. Se estará aplicando una teoría errónea, pero es indudable que sí tiene efectos en la práctica (14).

Lo que detectamos en esta indagación es que solemos reservar la ciencia práctica para las verdades, nuestras verdades. Dejémoslo de momento para continuar con Kant.

El segundo supuesto de no aplicabilidad tiene que ver, en la concepción kantiana, con los conceptos puros, aquellos que no están vinculados a la experiencia empírica, las verdades de razón que contraponía Leibniz a las "verdades de hecho". No entraremos en este punto; sólo indicar que también existe la "matemática aplicada".

\subsection{La completitud de la teoría a partir de la experiencia}

Profundicemos ahora en otro aspecto del primer supuesto de no validez de la teoría. El argumento de Kant ante la posible no validez de la teoría en la práctica es que esa teoría no se ha completado 
adecuadamente, esto es, que lo que falta en ese caso es precisamente más teoría. Su reflexión en este punto nos conduce al valor de la experiencia:

"Más aun contando con ese don natural, todavía puede haber una falta de premisas, esto es, puede suceder que la teoría sea incompleta y que acaso sólo quepa completarla mediante pruebas y experimentos ulteriores, a partir de los cuales el médico, el agricultor o el economista recién saldos de la escuela, pueden y deben arbitrar nuevas reglas para completar su teoría. Por tanto, cuando la teoría sirve de poco para la práctica, esto no se debe achacar a la teoría, si no precisamente al hecho de que no había bastante teoría, de modo que el hombre hubiera debido aprender de la experiencia la teoría que le falta, y que es verdadera teoría aunque él no esté en condiciones de proporcionarla por sí mismo, ni de presentarla sistemáticamente en proposiciones universales, como un maestro; por consiguiente, aunque no pueda pretender la denominación de médico teórico, agricultor teórico u otras por el estilo" (Kant 2006: 4; cursivas mías).

Hay en esa cita de Kant algo que interesa sobremanera resaltar y es su propuesta de aprender de la experiencia la teoría que falta. Con este llamado a aprender de la experiencia -y su aserto de que ello es "verdadera teoría"- Kant se alinea con la posición que vimos en Aristóteles y, en forma diferenciada, en Vico. Remite en efecto a Aristóteles y la pluralidad de "actividades de razón que expresan la verdad" puesto que Kant está otorgando a la experiencia del sujeto el valor de ser fuente de conocimiento (para complementar la teoría) y, además, dándole a ello el valor de ser "verdadera teoría", con lo cual está superando -como Aristóteles- el binomio simplificador teoría/práctica, puesto que hay teoría tanto en lo elaborado por el teórico como en lo que, completando lo anterior, pueda el sujeto (práctico) logre a partir de su experiencia. También es de interés su observación de que ello "es verdadera teoría aunque él no esté en condiciones de proporcionarla por sí mismo, ni de presentarla sistemáticamente en proposiciones universales, como un maestro".

Subyace aquí toda una pista para trabajar en ciencia social y antropología aplicada: a veces reducimos la teoría a lo que se presenta formalmente como tal, cuando puede presentarse bajo otros ropajes. Una cosa es el conocimiento teórico y otra su presentación, sistematización y formalización, o dicho de otra manera, la teoría no siempre se presenta por maestros y en formatos de suficiente universalización. La posición de Kant también le vincula a Vico desde el momento en que ese sujeto que elabora "verdadera teoría" a partir de su experiencia, es un hacedor, un agente que actúa en la práctica, elemento clave en la consideración de Vico sobre las posibilidades del conocimiento y su validación.

Lo anterior no debe conducir a la idea errónea de que Kant siempre valora la experiencia como fuente de conocimiento. Por el contrario, en su obra se muestra muy crítico con quienes quitan valor a la teoría otorgándoselo a la experiencia. Ahora bien, si en su defensa de la teoría Kant critica a quienes ven en la experiencia el verdadero saber, en su reflexión sobre la posibilidad de completar la insuficiente teoría desde la experiencia del sujeto, Kant está reconociendo explícitamente el valor de conocimiento teórico que puede haber en la experiencia: algo que aparecerá con fuerza en la noción de experiencia del pragmatista Dewey y en su proposición acerca de la "acción inteligentemente llevada", tal y como expondremos en el próximo ensayo.

Kant argumenta contra los críticos del valor de la teoría negando la posibilidad de dominar una determinada ciencia solo desde la práctica, sin teoría: "Así pues, nadie puede hacerse pasar por prácticamente versado en una ciencia y a la vez despreciar la teoría, sin reconocerse ignorante en su especialidad, por cuanto cree que con tanteos y experimentos realizados a ciegas, puede ir más allá del punto donde la teoría es capaz de conducirle, sin hacer acopio de ciertos principios (que constituyen, propiamente lo que se denomina teoría) y sin haber considerado globalmente su quehacer (lo cual, cuando se procede metódicamente, se llama sistema)" (Kant 2006: 4-5; cursivas mías).

Tan necesario es tener en cuenta los principios (la generalización y abstracción) como el quehacer (la práctica, la experiencia). 


\section{Teoría, práctica y praxis revolucionaria en Marx: las Tesis sobre Feuerbach (1845)}

En el pensamiento de Carlos Marx vamos a encontrar varias claves sobre la relación/articulación de teoría y práctica. La teoría en Marx es una teoría crítica y revolucionaria, lo primero porque la teoría ya incluye el empeño de transformación de la realidad estudiada, y lo segundo porque dicha transformación pretende un cambio radical de superación del sistema económico y social. Tanto desde el pensamiento filosófico y económico como desde la actividad política, y ligando ambos entre sí, Marx quiso llevar a cabo una nueva interpretación de los seres humanos y su mundo de explotación, alienación y desigualdad que sirviera a la voluntad de transformación profunda de dicho mundo. Si en Marx la teoría es una teoría crítica y revolucionaria, en su obra y vida política la práctica trató de ser ya no una práctica más -filosófica, científica o teórica- sino praxis política emancipadora. Como expuso, el ser humano no va a resolver sus problemas mediante la especulación sino a través de la praxis, de la acción iluminada, orientada, fundamentada o dirigida.

Esta conexión de teoría y praxis transformadora y revolucionaria no la encontramos en Aristóteles, Vico o Kant. Aristóteles vinculaba la teoría con otros saberes y con la sabiduría práctica, pero en Marx la teoría (crítica) permite fundamentar una praxis (revolucionaria), ese es su sentido último. Vico, como Marx, también se centra en el sujeto como alguien que hace el mundo y ve en los hechos y la práctica una fuente de verificación, pero en Marx esa agencia del sujeto se lleva al nivel de la transformación radical del mundo y de la posibilidad de emancipación de los seres humanos. En Kant, asistimos a la definición simultánea y complementaria (dialéctica en realidad) de teoría y práctica y a la defensa de la teorización y de su valor en la práctica de la moral, del derecho público y del derecho internacional, pero en Marx la defensa no será de la teoría en genérico, sino de aquella teoría crítica que reconoce la primacía del mundo material sobre el mundo de la idea y que está anclada en las relaciones y condiciones reales en las que viven los seres humanos.

Nos centraremos en sus aportaciones sobre el particular en las Tesis sobre Feuerbach (1845) y lo complementaremos con otras aportaciones de La ideología alemana. Las Tesis son un brevísimo -pero denso- texto que constituye uno de los textos clave en el pensamiento de Marx y, particularmente, en cuanto a su concepto de práctica y de la relación de ésta con la teoría. Se trata de uno de los textos del joven Marx; está escrito en la primavera de 1845 cuando Marx tenía veintisiete años. Fue publicado por Federico Engels en 1888, es decir cuarenta y tres años más tarde y a los cinco años de la muerte de Marx, constituyendo el apéndice de la edición del libro de Engels Ludwig Feuerbach y el fin la filosofía clásica alemana.

Para contextualizar las Tesis sobre Feuerbach (hegeliano de izquierdas) es conveniente indicar que en obras anteriores (15) Marx ya había realizado la crítica de Hegel, así como la de los "jóvenes hegelianos" o "hegelianos de izquierda". Nos referimos a la Crítica de la filosofía del derecho de Hegel escrita en 1843 y cuya introducción fue publicada en 1944 en París, en los Anales franco-alemanes; a esa obra le había sucedido Economía y Filosofía, también conocida como los Manuscritos económicos filosóficos, redactada en 1844 y publicada también después de su muerte. Del mismo año de las Tesis sobre Feuerbach (1845) es La sagrada familia o critica de la crítica crítica, escrita con Federico Engels y dirigida contra Bruno Bauer y otros hegelianos de izquierda. También de ese periodo del joven Marx es La ideología alemana (1845/1846), texto dirigido contra Feuerbach, Bauer y Stirner y que también se publicó póstumamente, así como La miseria de la Filosofía (1847) en la que rebate las posiciones de Proudhom en La Filosofía de la Miseria.

En esos textos Marx sostiene que la filosofía ha estado, por lo general, al servicio de la dominación, en tanto que propaga las ideas de la clase dominante; por ejemplo, presentando la propiedad privada como algo natural o eterno y no como algo gestado históricamente, en condiciones concretas y bajo relaciones reales. Pero igualmente en aquellos primeros textos Marx señalaba que la filosofía puede servir a la liberación o emancipación pudiendo iluminar una praxis transformadora. En lugar de la "especulación ebria" propuso la "filosofía sobria" (Reiss 2000: 102).

\subsection{Teoría, práctica y praxis en las Tesis sobre Feuerbach}


En las Tesis sobre Feuerbach la posición argumentativa de Marx es crítica no sólo con el idealismo sino con las versiones anteriores del materialismo, en las cuales ubica a Feuerbach, cuya filosofía materialista es denominada en este texto como antiguo materialismo o materialismo contemplativo. En ese sentido, hay que ubicar lo que Marx expone sobre la práctica dentro de su esfuerzo por definir el nuevo materialismo, lo que luego definirá como materialismo dialéctico y materialismo histórico.

La primera tesis, con la que empieza directamente el texto, es formulada así:

"El defecto fundamental de todo el materialismo anterior -incluido el de Feuerbach- es que sólo concibe las cosas, la realidad, la sensoriedad, bajo la forma de objeto o de contemplación, pero no como actividad sensorial humana, no como práctica, no de un modo subjetivo. De aquí que el lado activo fuese desarrollado por el idealismo, por oposición al materialismo, pero sólo de un modo abstracto, ya que el idealismo, naturalmente, no conoce la actividad real, sensorial, como tal. Feuerbach quiere objetos sensoriales, realmente distintos de los objetos conceptuales, pero tampoco él concibe la actividad humana como una actividad objetiva. Por eso, en La esencia del cristianismo sólo considera la actitud teórica como la auténticamente humana, mientras que concibe y fija la práctica sólo en su forma suciamente judaica de manifestarse. Por tanto, no comprende la importancia de la actuación "revolucionaria", "práctico-crítica" (Marx 1978: 7).

En esta tesis inicial, la primera crítica de Marx al materialismo anterior es que sólo considera la realidad como objeto y no también como práctica, como algo subjetivo. Esto es, "las cosas, la realidad" pueden ser contempladas como objeto pero deben serlo también en su componente subjetivo, "como práctica". Hay aquí un precedente claro de teorías posteriores de la acción que van a partir del sujeto humano activo, la agencia que diríamos hoy día. A los efectos de nuestra discusión es de especial interés que en esa dicotomía objeto/sujeto, lo objetivo/lo subjetivo, Marx equipara lo subjetivo a la práctica, término que aparece subrayado o enfatizado en el texto original. De ahí se deduce que la práctica es para él la acción humana subjetiva, capaz de incidir sobre la realidad. Es relevante asimismo la diferencia que establece Marx entre "como actividad sensorial humana" y "como práctica", pues la primera se refiere a lo que percibimos por los sentidos de las actividades humanas y lo segundo a la actividad consciente del sujeto.

La realidad se presenta tanto con una cara objetiva -como cosas, como actividades que podemos percibir- como con una cara subjetiva, como práctica humana subjetiva. En la realidad a analizar no solo hay "cosas" o "actividades sensoriales humanas" sino también prácticas subjetivas (con su creatividad, intereses, intenciones), y si las primeras permiten una consideración de objetos -y su "contemplación"las segundas requieren de otra aproximación, de "modo subjetivo". Considero que hay aquí también un claro precedente de la posición de Weber respecto a la metodología de las ciencias sociales, en el sentido de que pueden y deben combinar la explicación causal y la comprensión intuitiva (verstehen).

En la segunda frase de la tesis, Marx lleva a cabo una inferencia de enorme interés. Del aserto anteriormente comentado deduce que el idealismo pudo desarrollar una posición activa, recordemos por ejemplo la teoría de la libertad en Hegel, mientras que el materialismo previo no lo hizo, quedándose en posición pasiva, esto es no viendo al sujeto, a los humanos, como seres activos con respecto a su devenir, como actores o agentes en la terminología actual. Ahora bien, Marx indica también la carencia del idealismo, pues aunque tiene perspectiva de lo activo, lo hace "solo de un modo abstracto" ya que "no conoce la actividad real, sensorial, como tal".

Con esos mimbres, la crítica a Feuerbach ya está preparada, cosa que hace Marx en la tercera parte de esta primera tesis. El mérito de Feuerbach estriba en que "quiere objetos sensoriales, realmente distintos de los objetos conceptuales". En ese punto, su posición no es idealista. Ahora bien, su error según Marx está en no concebir la actividad humana como una actividad objetiva y por ello Feuerbach solo considera como auténticamente humano la actitud teórica y deja devaluada a la práctica. Aquí es clave interpretar correctamente lo que Marx quiere decir con la consideración de la actividad humana como una actividad objetiva. Antes en esta misma tesis, y en otros muchos pasajes de su obra, Marx estableció que lo objetivo es una forma de manifestación de lo real (como cosas) siendo la otra la cara de la realidad social el hacer humano, la práctica. 
El corolario es que a partir de esa limitación o error, Feuerbach no puede comprender la importancia de la actuación "revolucionaria", que Marx define o adjetiva como "práctico-crítica". Queremos entender aquí que esa actividad humana transformadora y revolucionaria tiene dos caras articuladas: por un lado es "práctica", esto es, cae dentro de la "actividad sensorial humana" -de lo concreto, etc.- y en cualquier caso no está (solo) en el terreno de lo conceptual; y, por otro lado, es "crítica", esto es, pone en cuestión lo establecido. En esta actividad revolucionaria práctico-crítica está ya la idea de praxis en el sentido de dialéctica entre teoría y práctica.

La segunda tesis es formulada así: "El problema de si al pensamiento humano se le puede atribuir una verdad objetiva, no es un problema teórico, sino un problema práctico. Es en la práctica donde el hombre tiene que demostrar la verdad, es decir, la realidad y el poderío, la terrenalidad de su pensamiento. El litigio sobre la realidad o irrealidad de un pensamiento que se aísla de la práctica, es un problema puramente escolástico" (Marx 1978: 7-8).

La glosa de esta segunda tesis requiere de tres pasos.

a) La primera afirmación no pude ser más provocadora y original al situar como problema práctico la cuestión de la verdad objetiva. No voy ahora a incidir en la enorme utilidad del concepto de "problema práctico" (16). Lo que nos interesa señalar aquí es el valor estratégico que para Marx tiene el mundo de la práctica a la hora de abordar ni más ni menos que la cuestión de la verdad objetiva.

b) La práctica aparece entonces como instancia verificadora de la corrección de la teoría, de su correspondencia con la realidad (lo que entendemos como el Momento III de la relación de teoría y práctica). Es lo que afirma Marx con contundencia en la segunda frase de la tesis: "es en la práctica donde el hombre tiene que demostrar la verdad, es decir, la realidad y el poderío, la terrenalidad de su pensamiento" (17).

Fijémonos que aquí Marx asocia la verdad a tres aspectos: primero, la "realidad", ya lo hemos mencionado en términos de la correspondencia entre teoría y realidad; segundo, el "poderío", lo que podemos interpretar como la capacidad, potencia o fuerza que tiene la teoría válida; y tercero, la "terrenalidad", esto es, la conexión directa de la teoría con la vida real o, dicho de otra forma, que tenga los pies en la tierra.

c) Lo anterior hila totalmente con la tercera frase sobre la "realidad o irrealidad de un pensamiento que se aísla de la práctica", pues si ello es así entonces Marx lo desprecia como mero asunto escolástico, esto es, fuera del mundo real.

En la tercera tesis este sujeto activo, que crea la realidad y es condicionado por ella, aparece expresado en los siguientes términos: "La teoría materialista de que los hombres son productos de las circunstancias y de la educación, y de que, por tanto, los hombres modificados son productos de circunstancias distintas y de una educación modificada, olvida que son los hombres, precisamente, los que hacen que cambien las circunstancias y que el propio educador necesita ser educado. Conduce, pues, forzosamente, a la división de la sociedad en dos partes, una de las cuales está por encima de la sociedad (así, por ejemplo, en Roberto Owen). La coincidencia de la modificación de las circunstancias y de la actividad humana sólo puede concebirse y entenderse racionalmente como 'práctica revolucionaria" (Marx 1978: 8; cursivas mías).

La cuarta tesis viene a concretar, con respecto al análisis incompleto del Feuerbach sobre la cuestión religiosa, el proceso o movimiento completo de la práctica revolucionaria:

"Feuerbach arranca de la auto enajenación religiosa, del desdoblamiento del mundo en un mundo religioso, imaginario, y otro real. Su cometido consiste en disolver el mundo religioso, reduciéndolo a su base terrenal. No advierte que, después de realizada esta labor, queda por hacer lo principal. En efecto, el que la base terrenal se separe de sí misma y se plasme en las nubes como reino independiente, sólo puede explicarse por el propio desgarramiento y la contradicción de esta base 
terrenal consigo misma. Por lo tanto, lo primero que hay que hacer es comprender ésta en su contradicción y luego revolucionarla prácticamente eliminando la contradicción. Por consiguiente, después de descubrir, v. gr., en la familia terrenal el secreto de la sagrada familia, hay que criticar teóricamente y revolucionar prácticamente aquella" (Marx 1978: 8; cursivas mías).

La quinta tesis vuelve a los términos de la primera para insistir en que "Feuerbach no contento con el pensamiento abstracto, apela a la contemplación sensorial; pero no concibe la sensoriedad como una actividad sensorial humana práctica" (Marx 1978: 8). Desde el punto de vista de Marx no basta con querer ir más allá de lo abstracto, otorgando validez a lo empírico o sensorial, sino que es preciso partir de que esa actividad sensorial y empírica no es como la de cualquier otro animal sino llevada a cabo por seres humanos dotados de conciencia y de práctica.

La sexta tesis tiene especial interés para comprender la concepción de Marx precisamente sobre esa naturaleza humana -de conciencia, de práctica- a la que nos acabamos de referir:

"Feuerbach diluye la esencia religiosa en la esencia 'humana'. Pero la esencia humana no es algo abstracto inherente a cada individuo. Es, en realidad, el conjunto de las relaciones sociales. Feuerbach, que no se ocupa de la crítica de esta esencia real, se ve, por tanto, obligado: 1) A hacer abstracción de la trayectoria histórica, enfocando para sí el sentimiento religioso (Gemüt) y presuponiendo un individuo humano abstracto, 'aislado'. 2) En él, la esencia humana sólo puede concebirse como "género", como una generalidad interna, muda, que se limita a unir naturalmente los muchos individuos" (Marx 1978: 9; cursivas mías).

Hay varios puntos que comentar aquí. Por un lado, la crítica de a-historicismo que hace Marx al estudio de la religión por Feuerbach y, sobre todo, el hecho de que esa falta de historicidad se deba, en la crítica de Marx, a la consideración de la esencia humana como algo abstracto y no como una totalidad concreta y cambiante: "el conjunto de las relaciones sociales" en cada momento histórico. Por otra parte, la observación de Marx de que esa concepción esencialista abstracta y, por lo tanto, a -histórica, conduce a separar el individuo del mundo social en el que hay que entenderlo, resultando un "individuo humano asilado" y por lo tanto imposible de comprender (se) y emancipar (se). Finalmente, también encontramos relevante el análisis de Marx de que la concepción esencialista abstracta y no histórica de la naturaleza humana lleva a una "generalidad interna, muda" que agrupa "naturalmente" a los seres humanos: hay aquí un precedente de los estudios posteriores que criticarán las explicaciones naturalistas de las diferencia y desigualdades humanas, por ejemplo, en Antropología del Género y en la corriente de Economía Política y Cultura.

La séptima tesis concreta los puntos anteriores de la siguiente forma: "Feuerbach no ve, por tanto, que el "sentimiento religioso" es también un producto social y que el individuo abstracto que él analiza pertenece, en realidad, a una determinada forma de sociedad" (Marx 1978: 9). Lo que venimos viendo sobre el énfasis de Marx en no quedarse en lo abstracto, en no desligarse el mundo real en tanto que mundo social, tiene siempre una conexión directa con la consideración de ese mundo real como mundo de la práctica.

A este respecto es muy significativa la tesis octava: "La vida social es, en esencia, práctica. Todos los misterios que descarrían la teoría hacia el misticismo, encuentran su solución racional en la práctica humana y en la comprensión de esta práctica" (Marx 1978: 9; cursivas mías). Aquí vuelve a insistirse en lo estratégico de la práctica ya formulado anteriormente desde la primera a la quinta tesis. La relevancia que da Marx a la práctica es tal que, según nuestra interpretación, le concede primeridad respeto a la teoría, y en la línea de lo que manifestamos al principio: esto es, de que la concepción marxiana supone una concepción inversa, crítica, alternativa, con respecto a la manera en la cual se ha considerado predominante y hegemónicamente la relación teoría-práctica en la historia de las ideas, en las ciencias sociales en general y, en particular, en la antropología.

La novena tesis vuelve a mostrar los límites de todo materialismo que se desligue de la práctica: "A lo que más llega el materialismo contemplativo, es decir, el materialismo que no concibe la sensoriedad 
como actividad práctica, es a contemplar a los distintos individuos dentro de la "sociedad civil" (Marx 1978: 9). Es interesante esta afirmación de Marx de que los individuos, las personas, son algo más que miembros de una sociedad civil, algo que se aborda también en la tesis décima en la que la sociedad humana o humanidad socializada aparece como algo más justo y completo que la mera sociedad civil: "El punto de vista del antiguo materialismo es la sociedad 'civil'; el del nuevo materialismo, la sociedad humana o la humanidad socializada" (Marx 1978: 9). Desde nuestra perspectiva, queremos resaltar como especialmente relevante -y valioso o útil para fundamental una antropología de o en la praxis- es lo estratégico de la consideración del mundo de la práctica precisamente para esa superación de la mera sociedad civil hacia la sociedad humana o la humanidad socializada.

La tesis más conocida, incluso famosa, y repetida con profusión, es la tesis undécima: "Los filósofos no han hecho más que interpretar de diversos modos el mundo, pero de lo que se trata es de transformarlo" (Marx 1978: 11). Aquí vuelve a mostrarse, y quizás con más contundencia aún, la finalidad última o de fondo de la teorización (critica) así como lo que hemos planteado como otorgación de la primeridad a la práctica. Complementariamente, vuelve a mostrarse la posición crítica de Marx ante teorizaciones que no ponen en cuestión el estado de cosas, el estado de desigualdad humana, y que por lo tanto colaboran con ello de una u otro forma.

\subsection{Práctica y teoría en La ideologia alemana}

Completemos la glosa de las Tesis sobre Feuerbach desde la lectura sobre las relaciones entre teoría, práctica y praxis, en La ideología alemana, publicado por Marx y Engels en 1845/46 y por lo tanto de elaboración simultánea con las Tesis. En el primer capítulo de La ideología alemana titulado "Feuerbach. Oposición ente las concepciones materialista e idealista" hay tres menciones relevantes para la cuestión que nos ocupa y que remiten, respectivamente, a los siguientes temas: a) la conciencia práctica y su relación con el lenguaje, b) las premisas prácticas para superar históricamente el estado general de enajenación, y c) la crítica de las "teorías perdidas en las nubes", esto es, desligadas de la práctica.

Comencemos por considerar las reflexiones sobre la conciencia, real y práctica, y su relación con el lenguaje, que hacen los autores en el tercer apartado de ese primer capítulo (18). Marx y Engels se refieren a la conciencia como rasgo caracterizador del ser humano:

"Solamente ahora, después de haber considerado ya cuatro momentos, cuatro aspectos de las relaciones originarias históricas, caemos en la cuenta de que el hombre tiene también conciencia. Pero, tampoco ésta es desde un principio una conciencia 'pura'. El espíritu hace ya tratado con la maldición de estar 'preñado' de materia, que aquí se manifiesta bajo la forma de capas de aire en movimiento, de sonidos, en una palabra bajo la forma del lenguaje. El lenguaje es tan viejo como la conciencia: el lenguaje es la conciencia práctica, la conciencia real, que existe también para los otros hombres y que, por tanto, comienza a existir también para mí mismo; y el lenguaje nace, como la conciencia, de la necesidad, de los apremios de relación con los demás hombres" (Marx y Engels 1978: 28-29; cursivas mías).

Como en las Tesis sobre Feuerbach aparece una mención explícita a la conciencia, pero no como conciencia pura sino práctica, ligada a las condiciones materiales de existencia y expresa en el lenguaje. Como rasgos definidores de lo humano, y específicos con respecto a los otros animales, además de la conciencia y el lenguaje -ambos ligados al mundo de la materia y de la práctica- Marx y Engels se refieren a la disponibilidad de actitudes en los seres humanos:

"Donde existe una actitud, existe para mí, pues el animal no tiene actitud ante nada ni, en general, podemos decir que tenga actitud alguna. Para el animal, sus relaciones con otro no existen como tales relaciones. La conciencia, por tanto, es ya de antemano un producto social, y lo seguirá siendo mientras existan seres humanos. La conciencia es, en principio, naturalmente, conciencia del mundo inmediato y sensorio que nos rodea y conciencia de los nexos limitados con otras personas y cosas, fuera del individuo consciente de sí mismo; y es, al mismo tiempo, conciencia de la naturaleza, que al principio se enfrenta al hombre como un poder absolutamente extraño, omnipresente e 
inexpugnable, ante el que la actitud de los hombres es puramente animal y al que se someten como el ganado; es, por tanto, una conciencia puramente animal de la naturaleza (religión natural)" (Marx y Engels 1978: 28-29; cursivas mías).

Un segundo análisis que encontramos significativo en ese primer capítulo de La ideología alemana se refiere a las condiciones históricas necesarias para acabar con la enajenación. En el apartado quinto (19) de dicho capítulo, Marx y Engels formulan el tipo de "premisas prácticas" que deben darse en la realidad social para que sea viable su transformación. Estas premisas prácticas son dos y deben darse simultáneamente; por un lado, la generación de masas de desposeídos y, por el otro, un alto grado de desarrollo universal de las fuerzas productivas:

"Con esta enajenación para expresarnos en términos compresibles para los filósofos, sólo puede acabarse partiendo de dos premisas prácticas. Para que se convierta en un poder insoportable, es decir, en un poder contra el que hay que hacer la revolución, es necesario que engendre a una masa de la humanidad como absolutamente desposeída y, a la par con ello, en contradicción con un mundo de riquezas y de educación, lo que presupone en ambos casos, un gran incremento de la fuerza productiva, un alto grado de su desarrollo" (Marx y Engels 1978: 34; cursivas mías).

Lo que interesa resaltar aquí es cómo, para Marx, el mundo social real es el mundo práctico, el mundo de la práctica. Con respecto a la segunda condición -desarrollo universal de las fuerzas productivas- añaden en un párrafo no por farragoso menos interesante, sobre todo desde la fase actual de globalización y aumento de las desigualdades:

"y, de otra parte, este desarrollo de las fuerzas productivas (que entraña ya, al mismo tiempo, una existencia empírica dada en un plano histórico-universal, y no en una existencia puramente local de los hombres) constituye también una premisa práctica absolutamente necesaria, porque sin ella sólo se generaría la escasez y por tanto, con la pobreza, comenzaría, a la par, la lucha por lo indispensable y se recaería necesariamente en toda la porquería anterior; y, además porque sólo este desarrollo universal de las fuerzas productivas lleva consigo a un intercambio universal de los hombres, en virtud de lo cual, por una parte, el fenómeno de la masa 'desposeída' se produce simultáneamente en todos los pueblos (competencia general), haciendo que cada uno de ellos dependa de las conmociones de los otros y, por último, instituye a individuos histórico-universales, empíricamente universales, en vez de individuos locales (20)" (Marx y Engels 1978: 34; cursivas mías).

Para un intento de fundamentación científico-crítica de la articulación de práctica y teoría en las ciencias sociales, y en la antropología en particular, encontramos aquí un punto de inspiración en el sentido de identificar esos individuos histórico-universales", esos sujetos de la emancipación a partir de prácticas locales y no locales fundadas en consideraciones éticas, jurídicas y políticas de relieve general o universal.

Una tercera referencia que encontramos significativa se ubica en el apartado octavo (21) del primer capítulo que estamos comentando de La ideologia alemana. La crítica teórica, en cuanto critica de las teorías idealistas, consiste en Marx en explicar esas teorizaciones idealistas a partir de las relaciones reales existentes, esto es, a partir del reino de la práctica. Así se expresan, por ejemplo, Marx y Engels en estos párrafos de La ideología alemana, donde se critica el localismo de las teorías "perdida en las nubes":

"Toda esta concepción de la historia, unida a la disolución y a las dudas y reflexiones nacidas de ella, es una incumbencia puramente nacional de los alemanes y sólo tiene un interés local para Alemania, como por ejemplo la importante cuestión, repetidas veces planteada en estos últimos tiempos, de cómo puede llegarse, en rigor, del reino de Dios al reino del hombre, como si este 'reino de Dios' hubiera existido nunca más que en la imaginación y los eruditos señores no hubieran vivido siempre, sin saberlo, en el reino del hombre, hacía el que ahora buscan los caminos, y como si el entretenimiento científico, pues no es otra cosa, de explicar lo que hay de curioso en esta formación 
teórica perdida en las nubes no residiese cabalmente, por el contrario, en demostrar cómo nacen las relaciones reales sobre la tierra" (Marx y Engels 1978: 41-42; cursivas mías).

Y Marx y Engels continúan:

"Para estos alemanes, se trata siempre, en general, de explicar los absurdos con que nos encontramos por cualquiera otras quimeras; es decir, de presuponer que todos estos absurdos tienen un sentido propio, el que sea, que es necesario desentrañar, cuando de lo que se trata es, simplemente, de explicar estas frases teóricas a base de las relaciones reales existentes. Como ya hemos dicho, la disolución real y práctica de estas frases, la eliminación de estas ideas de la conciencia de los hombres, es obra del cambio de las circunstancias y no de las deducciones teóricas. Para la masa de los hombres, es decir, para el proletariado, estas ideas teóricas no existen y no necesitan, por tanto, ser eliminadas, y aunque esta masa haya podido profesar alguna vez ideas teóricas de algún tipo, por ejemplo ideas religiosas, hace ya mucho tiempo que las circunstancias se han encargado de eliminarlas" (Marx y Engels 1978: 42; cursivas mías).

Todo ello lleva, como en las Tesis sobre Feuerbach, a postular la historicidad del pensamiento teórico, algo que nos interesa especialmente por cuanto remite a lo que postulamos al principio como el Momento I de la relación entre teoría y práctica: esto es, la generación histórico- concreta y práctica del conocimiento. Antes de considerar la aplicación de la teoría en la práctica (Momento II) es preciso analizar esa generación del conocimiento en un momento histórico que siempre es concreto, práctico. Engels en el viejo prólogo del Anti Dühring, escrito en 1878, lo expresó de la siguiente forma:

"El pensamiento teórico de toda época, incluyendo, por tanto, el de la nuestra, es un producto histórico que en periodos distintos reviste formas muy distintas y asume, por lo tanto, un contenido muy distinto. Como todas las ciencias, la ciencia del pensamiento es, por consiguiente, una ciencia histórica, la ciencia del desarrollo histórico del pensamiento humano. Y esto tiene también su importancia, en lo que afecta a la aplicación práctica del pensamiento en los campos empíricos" (Marx y Engels 1978: 59-60; cursivas mías) (22).

Si en los pensadores griegos -como Sócrates, Platón o Aristóteles- vimos que la ciencia teórica y la sabiduría práctica no se desconectaban sino que se postulaba su unión, en Marx se vuelve en cierta forma a ello al pretender vincular de nuevo el pensar y el ser.

\section{Síntesis, conclusiones y propuesta}

Con este artículo hemos comenzado una revisión de los hitos claves en la historia de las ideas acerca de la relación/articulación entre teoría y práctica. Sinteticemos en cuatro puntos las principales conclusiones y aprendizajes tras la lectura de Aristóteles, Vico, Kant y Marx.

\subsection{Pluralidad y diálogo de saberes}

Nos hemos acercado a la amplia concepción de Aristóteles en su Ética Nicomaquea sobre las diversas formas de conocimiento y saber, una línea de pensamiento que va mas allá del binomio o dualidad teoría/práctica, según el cual el saber está únicamente en el primer polo. La concepción aristotélica ha influido en muchos autores contemporáneos (por ejemplo, el filósofo Gadamer) y ha sido reevaluada en los últimos tiempos desde las ciencias sociales (Toulmin y Gustavsen 1996, Flybjerg 2001) y en antropología por Greenwood (2002). En próximos ensayos volveremos sobre estos desarrollos contemporáneos y sobre su aprovechamiento desde la antropología práctica.

En otro lugar he planteado como, en mi vida profesional como antropólogo, he comprobado la virtud y potencialidad de plantear la antropología aplicada, implicada y/o de orientación pública, como un diálogo de saberes. En esa ocasión puse el siguiente ejemplo: 
"Al trabajar como asesor y evaluador en el campo de las políticas públicas de inmigración y gestión de la diversidad, participando en formulación de planes de inmigración, convivencia o ciudadanía, y ya fuera con equipos de la administración central, autonómica o local, he participado en numerosas reuniones de trabajo con presencia dispar de políticos, responsables institucionales, técnicos, representantes de organizaciones no gubernamentales, líderes sociales y activistas locales, en las cuales he aprendido de otros conocimientos y he tratado de incorporarlos a los documentos y propuestas. Estoy convencido de que mi actitud de aprender de otros conocimientos y saberes no solo me ha permitido saber más y teorizar sino establecer buenas relaciones y hacer mejor mi aportación" (Giménez 2012).

Esa práctica profesional del diálogo de saberes

"exige ante todo plantear la relación no entre quien sabe y quienes no saben sino entre gentes que saben diferentes cosas de diferentes formas. Implica también no limitarse a reflexionar sobre lo que los demás saben o ignoran -algo que sin duda hay que hacer, pero que es insuficiente- sino entrar en una suma operativa e integradora de conocimientos. A todo esto, me temo, estamos poco acostumbrados los/las antropólogos/as. Exige asimismo practicar la escucha atenta del otro, establecer cauces de comunicación adecuados y saber traducir las complejidades del conocimiento teórico y abstracto" (Giménez 2012).

\subsection{Redefiniendo teoría y práctica: hacia un concepto ampliado y restringido de práctica}

Hemos observado la necesidad de definir lo que entendemos por teoría y práctica. y en este punto hemos encontrado de especial interés la conceptualización de Kant. Una de las dificultades en el avance en la articulación entre teoría y práctica es la excesiva polisemia y ambigüedad en el manejo del término práctica. Con frecuencia la concepción de "práctica" es tan amplia que abarca toda la acción social e incluso toda la realidad social. En nuestra perspectiva, una distinción necesaria y útil conceptualmente es la que hay que establecer entre "acción" y "práctica". Puede verse como una relación entre el todo y parte, entre el conjunto y el subconjunto, en el sentido de que no toda acción es una práctica, pero toda práctica sí es una acción. ¿Cuáles son, entonces, los rasgos definidores de una práctica?

A partir de la concepción kantiana de práctica, podría establecerse una serie de características o atributos presentes en toda práctica: 1) intencionalidad (realización de un fin), 2) fundamentación $u$ orientación (concreción de determinados principios representados con universalidad), 3) transformación o acción transformadora; y 4) carácter pautado. Veamos un ejemplo. Si tomamos una determinada práctica pedagógica, como puede ser la elaboración de un Plan Educativo de Centro (PEC) en una escuela, deberemos dar cuenta de: a) sus intenciones y fines, cómo cubrir el expediente administrativo que marca que dicho Plan debe hacerse obligatoriamente en tal plazo y forma; adecuar el centro educativo a la creciente diversificación cultural de sus aulas debido a la llegada de alumnado de origen extranjero...; b) cuáles principios educativos, éticos y de otro tipo inspiran y fundamentan ese Plan y su desarrollo; c) qué cambio o transformación de la vida del centro conlleva: reorganización, etc.; d) de qué forma ese Plan y los consiguientes procesos seguidos en su diseño, ejecución y evaluación, están organizado, que pautas colectivas se han seguido en ello (23).

En cualquier caso, y a partir de estas primeras reflexiones, las nociones ampliadas u restringidas de práctica y de teoría será otro de los hilos conductores que seguiremos en los próximos ensayos.

\subsection{Primeridad de la práctica y concepción holística de la relación}

Las aportaciones consideradas -sobre todo las de Aristóteles y Marx-y otras que analizaremos, permiten superar la concepción hegemónica acerca de esta cuestión, esto es, la idea de que: a) dicha relación es una relación unidireccional: "primero la teoría, después la práctica"; b) una concepción que concede siempre el protagonismo a la teoría: de ella se parte, ella tiene el rango superior en cuanto al saber; no hay saber en la práctica, etc.; c) que limita o reduce las interacciones entre el mundo de la práctica y el de la teoría a la mera aplicación de ésta. 
Hemos ido señalando momentos diferentes de esa relación, mencionados ya en la Introducción en cuanto que hilos conductores de la revisión. Tenemos, por un lado, (Momento I) todo lo relativo a la generación de las teorías filosóficas y científicas en contextos históricos concretos, esto es, en mundos prácticos configurados por formaciones sociales con sus modos de producción, relaciones de poder y superestructuras políticas e ideológicas. En este punto son claves las aportaciones de Vico y Marx sobre la historicidad del conocimiento, línea cuya pista seguiremos en autores contemporáneos. Si se quiere conocer la relación de facto entre teorías y prácticas es necesario analizar y tener en cuenta cómo está organizado el conocimiento y su gestión en cada contexto histórico, y de qué manera ello influye o condiciona (no determina) qué y cómo se estudia, quiénes lo hacen, qué se fomenta y que se limita, qué se permite y qué se prohíbe, etc. La actividad teórica es ella misma una práctica cuya naturaleza y lógica no es solo intelectual, sino también emocional, relacional y política, y sobre todo en determinados ámbitos del saber.

Tenemos también (Momento II) todo lo relativo a los procesos de uso, utilización y aplicación de los conocimientos. Es ésta la dimensión que ha sido privilegiada tradicionalmente al analizar la relación de teoría y práctica, la que ha adjetivado la matemática aplicada, la psicología aplicada, la economía aplicada o la antropología aplicada. Se cuenta con un determinado conocimiento y se aplica a esto o aquello, en éste o aquel contexto, para abordar determinada situación. Hemos visto cómo en la filosofía griega clásica el saber es necesario para la virtud y cómo no estaban tan marcadas las fronteras entre el mundo del conocimiento y el de los valores o las virtudes. Posteriormente, hemos reparado cómo en Kant la aplicación es explícitamente considerada como una mediación entre la teoría y la práctica y cómo en Marx la teoría es revolucionaria porque se aplica, como praxis, a la transformación del sistema social.

Tenemos luego (Momento III) todo lo concerniente a la comprobación/refutación o verificación/falsación de las teorías en la práctica, o sería más exacto decir validación de la teoría también mediante la praxis, dado que esta posibilidad no niega en absoluto los otros procedimientos de validación de la teoría (demostración, experimentación, predicción). En este campo las aproximaciones son diversas. En Vico, esta cuestión aparece en el centro de la discusión y de la propia metodología de la Nueva Ciencia que postula a partir del verum factum. En Kant, la teoría si es correcta tiene entonces su correlato en la práctica, y su disertación de 1793 está precisamente encaminada a refutar el dicho "es válido en la teoría pero no en la práctica". En Marx, la praxis revolucionaria, transformadora, supone la confirmación de la validez del análisis del materialismo histórico y dialéctico.

Finalmente (Momento IV) es preciso considerar el conjunto de temáticas referentes a la teorización desde la práctica. Como en el punto anterior, aquí es igualmente más exacto decir teorización también desde la práctica, puesto que la mayor parte de la teorización se produce desde el análisis y la interpretación de los hechos, datos e informaciones con las que se cuenta. En este Momento IV de la relación teoría/práctica, que igualmente iremos rastreando en próximos ensayos y diversos autores contemporáneos, las posiciones más relevante son las de Vico y Marx. En Vico, puesto que parte precisamente de que el conocimiento científico social es posible dado que somos hacedores de la realidad que estudiamos 0 , dicho de otra manera, en las ciencias sociales estudiamos la realidad que hemos hecho. $Y$ desde Marx a partir de la espiral dialéctica de la praxis, cuyas fases interrelacionadas pueden sintetizarse así: a) voluntad inicial y continuada por una práctica transformadora; b) uso de la reflexión rigurosa y sistemática sobre la realidad con objeto de transformarla, esto es, mejorarla según los valores éticos explicitados; c) orientación y fundamentación de nuevas prácticas de intervención a partir de las premisas teóricas iniciales y de la reflexión acerca de la confirmación y reajuste de los planteamientos; d) sistematización de la experiencia orientada por la teoría y emergencia de nueva teoría (ideas, conceptos, tesis, etc.).

\subsection{Una propuesta de articulación para la praxis antropológica}

Para concluir, quisiéramos -pasando del plano fáctico al normativo- hacer una propuesta ya no en cuanto a la relación entre teoría y práctica sino en cuanto a su articulación. La revisión realizada permite ir fundamentando algo que hemos ido desarrollando desde la antropología práctica a lo largo de los años, si bien de manera dispersa y sin el fundamento que proveen estos y otros autores y obras. Se trata de 
construir, en el campo de la antropología aplicada, implicada y de orientación pública, una articulación entre pensamiento y acción con los siguientes rasgos.

Primero, que sea una articulación científicamente fundamentada en el doble sentido de: a) estar basada en el rigor de la teoría científica y sus procedimientos, explicitando especialmente de que teoría de la acción se parte; b) inspirarse en aportaciones heurísticamente ricas -como las señaladas en Aristóteles, Vico, Kant o Marx, y otros autores que iremos considerando- sobre la conexiones entre las proposiciones científicas y las acciones recurrentes y pautadas.

Segundo, una articulación de carácter dialéctico, esto es, que establezca una praxis antropológica. En el caso de las experiencias o proyectos de antropología aplicada se trata, por ejemplo, de participar en proyectos de intervención social en los cuales se lleven a cabo determinadas acciones orientadas en determinados enfoques y establecer sistemas de seguimiento y análisis que permitan vincular -al menos en parte- los resultados e impactos a los planteamientos teórico-conceptuales y, dialécticamente, volver a teorizar desde la experiencia práctica.

Tercero, una articulación éticamente implicada, en el sentido de que estén explicitados los valores en los que se basa el proyecto práctico. Si la dimensión ética es relevante y necesaria en toda actividad humana y en la científica en particular, lo es más aún en el caso de la ciencia social aplicada y de los proyectos orientados o de transferencia. Sanromán (2006) ha señalado acertadamente el "plus de responsabilidad" que debe exigirse a -y que deben exigirse- quienes se involucran en este tipo de iniciativas, desde el momento en que se está tratando precisamente de incidir sobre la realidad social, en un sentido u otro.

Cuarto, una articulación de práctica/teoría con orientación pública, esto es, que sea sensible intelectual, moral y políticamente con respecto a los retos del horizonte histórico donde se expresa, tratando de abordar algunos de los problemas del mundo contemporáneo y de hacer alguna contribución desde la antropología y en cuanto que antropólogo/a. Una orientación pública que no afecta solo a las temáticas (de amplio interés público y social) sino también a las motivaciones (aportar una mirada diferente, antropológica, sobre una cuestión de actualidad; defender una causa que se considera justa, etc.), a las audiencias (tan amplias como sea el conjunto de interesados y/o afectados por esa problemática) y a los formatos (mucho más variados que el ensayo científico, informe o la tesis, utilizando el artículo periodístico, el programa de radio, el documental televisivo, el foro en Internet, u otros) Concretamente, la orientación pública de la articulación teoría/práctica supone que el científico social se implica en experiencias o proyectos donde hay otros actores institucionales y sociales, de relevancia pública, con los cuales se colabora, entre otras cosas reconociendo y valorando los saberes y conocimientos presentes en ese espacio público.

Quinto, una articulación técnicamente operativa, por cuanto debe "desplegarse" de tal forma que resulte útil en la práctica del proyecto, experiencia o iniciativa. No es éste el lugar para un tratamiento sistemático de esta dimensión técnica, pero sí mencionaré -con objeto de justificar este rasgo- algunas de las herramientas que he ido configurando en el transcurso de los proyectos aplicados y que enseño habitualmente en los estudios de grado y posgrado de antropología. Algunas de ellas aparecen referidas y clasificadas en Giménez (2012) y habrá ocasión para referirme a ellas en trabajos de carácter metodológico. Algunas técnicas de trabajo aplicado que resultan particularmente adecuadas para concretar y operativizar la articulación de teoría y práctica que se propone son, entre otras, las siguientes:

a) La formulación de problemas prácticos, técnica mediante la cual se incorpora el mundo de la práctica desde el mismo planteamiento inicial del proyecto, pues se complementa la dimensión teórica habitual de la "formulación del problema" con el planteamiento del problema -o de los problemas- en términos de las necesidades, carencias o demandas sociales.

b) Los procedimientos de deducción o inferencia de las implicaciones prácticas que subyacen en las premisas teóricas y en los elementos conceptuales de referencia del proyecto (por ejemplo, en el concepto de "Cultura"); herramienta que permite conectar teoría y práctica no ya en el plano general sino 
c) La doble traducción, esto es, traducción inicial (1) de la demanda a su planteamiento en términos antropológicos, y traducción posterior (2) de las conclusiones obtenidas tras el análisis al lenguaje predominante entre los protagonistas; este instrumento de la doble traducción debe ubicarse en el reto crucial de la comunicación entre el/la antropólogo/a y los participantes en la experiencia; comunicación que debe ser lo más dialógica y efectiva posible.

d) Los procedimientos para la teorización desde la práctica, lo cuales van desde la vía de la sistematización de la experiencia (pasando de la enorme casuística de las acciones a un primer nivel de generalización, camino de la necesaria abstracción que requiere toda teoría) hasta la labor participativa de crítica y reajuste de las premisas teóricas iniciales.

A partir de la revisión de estos primeros autores y textos claves, ha quedado abierta una amplia agenda de trabajo que iremos abordando en próximos ensayos. Disponemos ahora de varios hilos conductores (pluralidad y dialogo de saberes; noción amplia y restringida de práctica; primeridad de la práctica; diferentes momentos y procesos en la relación de teoría y práctica; características y operatividad de un posible modelo articulador de ambas) para poder seguirlos y ampliarlos a partir de Dewey, Gramsci, Mannheim, Habermas y otros pensadores, así como para analizarlos específicamente en la historia del pensamiento antropológico.

\section{Notas}

1. Agradezco a Olga Díez y a Pía Calderón su valiosa ayuda bibliográfica y documental.

2. En un segundo ensayo abordaremos desde la propuesta de Vilfredo Pareto de separación radical de teoría y práctica hasta las aportaciones pragmatistas de John Dewey sobre conocimiento y experiencia, y la acción inteligentemente llevada; coronando ese recorrido con las filosofías de la práctica de Benedetto Croce y Antonio Gramsci, así como la posición de Karl Mannheim desde la sociología del conocimiento. En un tercer ensayo consideraremos aportaciones formuladas en las décadas de los sesentas y setentas por Hans-Georg Gadamer, Giovanni Sartori, Michel Foucault, Jurgen Habermas y Pierre Bourdieu. En un cuarto ensayo consideraremos las aportaciones más recientes de Stephen Toulmin, Bjorn Gustavsen, Boaventura Sousa-Santos y Bent Flybjerg.

3. Tras la revisión de los autores mencionados, y al hilo de esa discusión, tenemos previsto recopilar, en ensayo específico, las posiciones y aportaciones que consideramos más relevantes sobre la relación larticulación de teoría y práctica en la historia de la antropología. Se trata de reconsiderar, desde las implicaciones deducidas en éste y sucesivos ensayos, los debates históricos en torno a la antropología aplicada e involucrada o engaged anthropology (Eriksen 2005) que tuvieron lugar antes de la crisis de paradigmas de la década de los setentas (prestando especial atención a la figura de Ángel Palerm) hasta aportaciones posteriores como las de Davyd Greenwood o las de Carole Hill, Marietta Baba, Kathriyn A. Kozaitis y otros promotores del importante simposio del año 2000 sobre The Unity of Theory and Practice in Anthropology: Rebuilding a Fractured Synthesis.

4. Véase, al respecto, Manuel Jiménez Redondo (2005), "Gadamer sobre el concepto aristotélico de phrónesis", ENDOXA. Series filosóficas, n² 20: 295-323. UNED.

5. Sigo la edición de 2010 a cargo de Silvia Catalá y F. Javier Lorente en la colección Grandes Obras del Pensamiento (Ediciones El País); si bien confrontándola con otras, especialmente con la versión de Antonio Gómez Robledo en la publicación por la editorial Porrúa de México, cuya primera edición fue en 1967. Así, el texto citado, es traducido así por Gómez Robledo: "Sean en número de cinco las virtudes 
por las cuales, afirmando o negando el alma alcanza la verdad, a saber: arte, ciencia, prudencia, sabiduría, intuición" (1981: 75).

6. Hay en Aristóteles una valoración tan positiva de la razón que parece casi una exaltación de lo razonable y de la razonabilidad.

\section{N. Abbagnano, Filosofia Moderna, 1988: 193.}

8. Esto es, la verificación de la teoría en la práctica se da -desde un punto de vista ontológico- "tras" o "dado que antes ha habido" la generación del conocimiento en los contextos del mundo de las prácticas (primer momento) y el uso útil o aplicación en la práctica de dicho conocimiento (segundo momento). Tras los procesos de verificación y validación en la práctica, al que nos hemos referido con Vico, podemos ubicar la teorización desde la praxis (cuarto momento).

9. Kant explica aún con más detalle la estructura tripartita del ensayo y la selección de las temáticas: "Presentaremos, pues, la relación entre teoría y práctica en tres apartados: primero, en la moral en general (con las miras puestas en el bien de todo hombre); segundo, en la política (en relación con el bien de los Estados); tercero, desde un punto de vista cosmopolita (con vistas al bien del género humano en su conjunto, y en tanto que se lo concibe progresando hacia ese bien a través de la serie de todas las generaciones futuras). Los títulos de los apartados expresarán -por razones que se desprenden del propio tratado- la relación entre teoría y práctica en la Moral, en el Derecho Político y en el Derecho Internacional" (Kant 1793: 2006: 6-7).

10. En cualquier caso y desde el punto de vista de las ciencias sociales contemporáneas, y particularmente de la antropología, nos interesa aquí superar el estricto y rígido binomio universal/particular, incorporando por ejemplo la categoría de lo regular y de las regularidades, esto es, aquello que suele ocurrir no siempre y en todo lugar, sino solo en un determinado grupo o conjunto de situaciones y procesos. Así, por ejemplo, en los trabajos de evolucionismo multilineal de Steward (1955) y otros autores cuando identifican las regularidades secuenciales seguidas por las sociedades hidráulicas. O cuando Scudder (1995) formula las cuatro fases que pueden ser identificadas en los procesos de reasentamiento de poblaciones que estudió. a las que responden los procesos de reasentamiento que estudió. En esas propuestas teóricas las regularidades se encuentran a medio camino entre los universales y los particulares (véase también Kottak 1981).

11. Hay aquí algo que debemos precisar. La teoría se aplica a una determinada realidad, y en ese proceso concurren multitud de condiciones, toda una casuística de particularismo. Ahora bien, cuando hablamos de articular teoría y práctica, podemos referirnos a eso (en una concepción general y amplia de práctica) o podemos referirnos a su aplicación a determinadas prácticas concretas y particulares.

12. De nuevo, esto ayuda en cuanto sigue acotando el término, sin embargo hemos de interpretar con precisión a qué se refiere Kant pues según lo que entendamos puede subyacer, a nuestro entender, algún que otro problema de fondo. Teniendo en cuenta la concepción de universalidad que hay en Kant (por ejemplo, en su ética) debemos entender esta última idea en el sentido de que toda práctica remite a principios válidos plenamente para quienes la realizan o, como diríamos hoy, plenamente válidas para los actores protagonistas de tales prácticas.

13. Un inciso sobre la categoría de lo justo en la teoría y/ o en la práctica, adjetivo incluido por Sartori si bien Kant se refiere a correcto: "tal vez eso sea correcto en teoría pero no sirve en la práctica". Nos parece que aquí se incorpora -por Sartori- una cuestión normativa y de derecho -de iure- que distorsiona un tanto los planteamientos. Una cosa es que, como venimos insistiendo, la aplicabilidad requiera de la explicitación de los valores que guían la acción práctica (dado que se trata de incidir sobre la realidad de forma intencionada y, por lo tanto, en un determinado sentido) y otra que una teoría pueda o deba ser justa, e incluso que pueda o deba serlo la acción orientada teóricamente.

14. Consideremos un par de ejemplos, el de las teorías nazis sobre la raza y la eugenesia. Esas posiciones estaban fundamentadas con una ideología cientificista, habiéndose fundado para ello un 
Instituto de Eugenesia. Esa era la fundamentación teórica para la acción eugenésica. Veamos un segundo ejemplo en relación con las teorías del desarrollo económico y social. La posición teórica de Rostov, dentro del paradigma de la Modernización, acerca de "los cinco estadios del desarrollo" fue debidamente criticado -y refutado, desde mi perspectiva- por Gunder Frank y otros estudiosos de la teoría de la dependencia. Pero ello no quita que las concepciones unilineales de Rostow tuvieran influencia en la práctica.

15. $\mathrm{Y}$ todas ellas tras su tesis doctoral de 1841 sobre Diferencia entre la filosofía de la naturaleza en Demócrito y la de Epicuro.

16. Algo que explico en la asignatura de antropología aplicada, en el sentido de que en ésta, a diferencia de lo que ocurre con la antropología básica -o solo teórica, pues en la aplicada también hay o debe haber teoría pues es teórico práctica- podemos y debemos formular no solo, o no tanto, problemas teóricos sino prácticos.

17. Como se ha señalado "la prueba de la verdad de las teorías está en su eficacia o efectividad para producir los fenómenos que predice" (como señala González de la Fe 1998: 594).

18. Apartado titulado en la edición de la Obras Escogidas de Marx y Engels (1978) de la siguiente forma: "Relaciones históricas primarias, o aspectos básicos de la actividad social: producción de medios de subsistencia, creación de nuevas necesidades, reproducción del hombre (la familia), relación social, conciencia".

19. Titulado "Desarrollo de las fuerzas productivas como premisa material del comunismo".

20. Y continúan Marx y Engels: "Sin esto 1) el comunismo sólo llegaría a existir como fenómeno local, 2) las mismas potencias de relación no podrían desarrollarse como potencias universales y, por tanto, insoportables, si no que seguirían siendo simples "circunstancias" supersticiosas de puertas adentro, y 3) toda ampliación, empíricamente, sólo puede darse como la acción "coincidente" o simultánea de los pueblos dominantes, lo que presupone el desarrollo universal de las fuerzas productivas y el intercambio universal que lleva aparejado" (Marx y Engels 1978: 34; cursivas mías).

21. Titulado en la edición que manejamos "Inconsistencia de toda la concepción anterior, idealista de la historia, sobre todo de la filosofía alemana posthegeliana".

22. Esa historicidad del pensamiento teórico la fundamenta Engels en la propia lógica y hasta en la dialéctica: "la teoría de las leyes del pensamiento no es ni mucho menos, una "verdad eterna" establecida de una vez para siempre como se lo imaginaba el espíritu del filisteo en cuanto oye la palabra "lógica". La misma lógica formal sigue siendo objeto de enconados debates con Aristóteles hasta nuestros días. Y por lo que la dialéctica se refiere, hasta hoy sólo ha sido investigada determinantemente por dos pensadores: por Aristóteles y por Hegel. Y precisamente la dialéctica es la forma más importante del pensamiento para las modernas Ciencias Naturales, ya que es la única que nos brinda la analogía y, por tanto, el método para explicar los procesos de desarrollo de la naturaleza, las concatenaciones es sus rasgos generales, y el tránsito de un terreno a otro de investigación" (Marx y Engels 1978: 59-60; cursivas mías).

23. He aquí otro ejemplo: si tomamos una determinada práctica electoral, como puede ser, el diseño y desarrollo de la campaña electoral de un partido político, deberemos igualmente considerar: a) sus para qué: ganar las elecciones, aumentar el apoyo social, aprovechar para concienciar); b) sobre qué principios parece fundamentarse o justificarse: servicio público, regeneración, compromiso social; c) qué transformación implica: cambiar la intención de votos de determinados ciudadanos, cambiar la correlación de fuerzas, reformar aspectos de la vida de la comunidad o país una vez ganada las elecciones u obtenido un respaldo considerado suficiente; y d) las pautas a la que responde dicha campaña: pautas de discurso, organizativas, de funcionamiento, de reglamentación, financieras. 


\section{Bibliografía}

Abbagnano, Nicolás

1988 Filosofía contemporánea, vol. 6 de Historia del Pensamiento. Editorial Sarpe.

Aristóteles

1967 Ética Nicomaquea. Política. México D.F., colección "Sepan cuantos...", Editorial Porrúa, 1981.

2010 Ética Nicomaquea. Ética Eudemiana. Madrid, colección Grandes Obras del Pensamiento, Ediciones El País.

Aubenque, Pierre

1999 La prudencia en Aristóteles. Barcelona, Editorial Crítica. (Edición original en francés, 1963).

Eriksen, Th. G.

2005 Engaging Anthropology. The case for a public presence. Nueva York, Borg.

Flyvbjerg, Bent

2001 Making Social Science Matter: Why Social Inquiry Fails and How Can Succeed Again. Londres, Cambridge University Press.

Giménez, Carlos

1999 "El antropólogo como asesor. Dos experiencias de consultoría en migraciones e interculturalidad", Antropología más allá de la academia. Salamanca, Actas del VIII Congreso de Antropología.

2011 "Hacia una nueva etapa de práctica profesional en la antropología. Retos y propuestas", Lugares, tiempos y memoria. La antropología ibérica en el siglo XXI. León, Actas del XII Congreso de Antropología.

Gledhill, J.

2000 El poder y sus disfraces. Barcelona, Ediciones Bellaterra.

Gomá, J.

2010 "Concordia, o estar de acuerdo consigo mismo y con los demás", Prefacio a Ética Nocomaquea. Ética Eudemiana. Madrid, Ediciones El País: 9-20.

Gómez Robledo, A.

1981 "Introducción“, Ética Nicomaquea. Política. México D. F, Editorial Porrúa: 7-30.

Gónzález, Moisés (y Josep Martínez)

1998 Autobiografía de Giambattista Vico. Madrid, Siglo XXI.

Greenwood, David

2000 "De la observación a la investigación-acción-participativa: una visión crítica de las prácticas antropológicas", Revista de Antropología Social, nº 9: 27-49.

2002 "El sentido práctico de la antropología", Actas del VI Congreso de Antropologia Aplicada. Granada, 14-16 de noviembre.

Hill, Caroll E. (y Marietta L. Baba) (eds.)

2000 The Unity of Theory and Practice in Anthropology: Rebuilding a Fractured Synthesis. Napa Bulletin. National Association for the Practice of Anthropology, American Anthropological Association.

Jiménez, Manuel

2005 "Gadamer sobre el concepto aristotélico de phrónesis", ENDOXA. Series filosóficas, n 20: 295323. UNED.

Kant, Inmanuel 
2006 Teoría y práctica. Madrid, Tecnos. (Textos originales de 1793 y 1797).

Marx, Karl

1970 Manuscritos. Economía y filosofía. Madrid, Alianza Editorial. 3a edición (elaborados en 1844).

Marx, Karl

1978 Tesis sobre Feuerbach, Obras Escogidas, vol. I. Moscú, Editorial Progreso. (Texto de 1845, edición original 1888).

Marx, Karl (y Frederic Engels)

1978 "Feuerbach. Oposición entre las concepciones materialista e idealista", La ideología alemana, Obras Escogidas, vol. I. Moscú, Editorial Progreso. (Texto de 1845/1846).

Reiss, E.

2000 Una guía para entender a Marx. Madrid, Siglo XXI.

Sanromán, Teresa

2006 "¿Acaso es evitable? el impacto de la antropología en las relaciones e imágenes sociales”, Revista de Antropología Social, nº 15: 373-410.

Sartori, Giovanni

1996 La política. Lógica y método en las ciencias sociales. México, Fondo de Cultura Económica (cuarta reimpresión).

Steward, Julien

1955 A theory of cultural change. Illinois, Chicago University Press.

Toulmin, Stephen (y Bjon Gustavssen) (eds.)

1996 Beyond Theory. Amsterdam y Philadelphia, John Benjamins.

Vico, Giambattista

1985 Ciencia Nueva, 2 vols. Barcelona, Editorial Orbis.

Viqueira, Carmen

2004 El método científico y el pensamiento productivo. Un análisis crítico del método antropológico, Documentos del Seminario de Primavera. Universidad Iberoamericana. México, D. F.

Willingen, John van

1985 Applied Anthropology. An Introduction. Westport, CT, Bergin \& Garvey.

Zamora, J. M.

2001 "Sophia y phrónesis en Aristóteles: Ética a Nicómaco VI, 7, 1141 a 81411 b 22", Taula, quaderns de pensamet, $\mathrm{n}^{\circ}$ 35-36: 37-51.

Zozaitis, Kathreen

1999 "The Rise of Anthropological Praxis", en Carole E. Hill y Marietta L. Baba (eds.), The unity of theory and practice in anthropology: rebuilding a fractured synthesis. Napa Bulleting, $\mathrm{n}^{\circ} 18$, National Association for the Practice of Anthropology. 